\title{
Functional Characterization of a Vesicular Glutamate Transporter in an Interneuron That Makes Excitatory and Inhibitory Synaptic Connections in a Molluscan Neural Circuit
}

\author{
Jian Jing, ${ }^{1,2 *}$ Vera Alexeeva, ${ }^{2 \star}$ Song-an Chen, ${ }^{1 \star}$ Ke Yu, ${ }^{1 \star}$ Michael R. Due, ${ }^{2}{ }^{\circ}$ Li-nuo Tan, ${ }^{1}$ Ting-ting Chen, ${ }^{1}$ \\ (DD)Dan-dan Liu, ${ }^{1}$ Elizabeth C. Cropper, ${ }^{2}$ Ferdinand S. Vilim, ${ }^{2}$ and Klaudiusz R. Weiss ${ }^{2}$ \\ ${ }^{1}$ State Key Laboratory of Pharmaceutical Biotechnology, Nanjing Advanced Institute for Life Sciences, Nanjing University School of Life Sciences, Nanjing, \\ Jiangsu 210093, China and 2Department of Neuroscience and Friedman Brain Institute, Icahn School of Medicine at Mount Sinai, New York, New York \\ 10029
}

Understanding circuit function requires the characterization of component neurons and their neurotransmitters. Previous work on radula protraction in the Aplysia feeding circuit demonstrated that critical neurons initiate feeding via cholinergic excitation. In contrast, it is less clear how retraction is mediated at the interneuronal level. In particular, glutamate involvement was suggested, but was not directly confirmed. Here we study a suspected glutamatergic retraction interneuron, B64. We used the representational difference analysis (RDA) method to successfully clone an Aplysia vesicular glutamate transporter (ApVGLUT) from B64 and from a glutamatergic motor neuron B38. Previously, RDA was used to characterize novel neuropeptides. Here we demonstrate its utility for characterizing other types of molecules. Bioinformatics suggests that ApVGLUT is more closely related to mammalian VGLUTs than to Drosophila and Caenorhabditis elegans VGLUTs. We expressed ApVGLUT in a cell line, and demonstrated that it indeed transports glutamate in an ATP and proton gradient-dependent manner. We mapped the ApVGLUT distribution in the CNS using in situ hybridization and immunocytochemistry. Further, we demonstrated that B64 is ApVGLUT positive, supporting the idea that it is glutamatergic. Although glutamate is primarily an excitatory transmitter in the mammalian CNS, B64 elicits inhibitory PSPs in protraction neurons to terminate protraction and excitatory PSPs in retraction neurons to maintain retraction. Pharmacological data indicated that both types of PSPs are mediated by glutamate. Thus, glutamate mediates the dual function of B64 in Aplysia. More generally, our systematic approaches based on RDA may facilitate analyses of transmitter actions in small circuits with identifiable neurons.

Key words: Aplysia; central pattern generator; feeding; glutamate; interneuron; vesicular glutamate transporter

\section{Introduction}

Circuit operation depends on the interplay between circuit elements and their neurotransmitters, necessitating the continued need to localize neurotransmitters to specific neurons and characterize their actions. A common approach to study transmitter actions is to use pharmacological reagents. Another important approach is to identify molecules involved in neurotransmission,

\footnotetext{
Received Jan. 13, 2015; revised May 7, 2015; accepted May 7, 2015.

Author contributions: J.J., E.C.C., F.S.V., and K.R.W. designed research; J.J., V.A., S.-a.C., M.R.D., T.-t.C., and F.S.V. performed research; J.J., V.A., S.-a.C., K.Y., L.-n.T., T.-t.C., and D.-d.L. analyzed data; J.., E.C.C., and K.R.W. wrote the paper.

This work was supported by the National Institutes of Health (NS066587, NS070583, and MH051393), the National Natural Science Foundation of China (31371104), and the National Undergraduate Innovation Program and National Natural Science Foundation of China grants (J1103512 and J1210026). We thank Drs. J.-J. Wang, J.-N. Zhu, and Q.-X. Zhuang for providing picrotoxin.

*J.J., V.A., S.-a.C., and K.Y. contributed equally to this work.

The authors declare no competing financial interests.

Correspondence should be addressed to Jian Jing, School of Life Sciences, Nanjing University, Jiangsu 210093, China. E-mail:jingj01@live.com.

DOI:10.1523/JNEUROSCI.0180-15.2015

Copyright $\odot 2015$ the authors $\quad 0270-6474 / 15 / 359137-13 \$ 15.00 / 0$
}

e.g., vesicular transporters of specific transmitters. The two approaches require different techniques and are often separately implemented. Here we sought to combine the two by studying identified neurons in the Aplysia feeding circuit (Cropper et al., 2004; Jing, 2009). To characterize a vesicular transporter we used our recently described representational difference analysis (RDA) method (Jing et al., 2010). We studied glutamatergic neurons, which are of particular interest, because although glutamate is the primary excitatory transmitter in the mammalian brain (Jahr and Lester, 1992), in Aplysia this type of function is also subserved by ACh. Indeed, in the Aplysia feeding circuit, ACh appears to serve as the primary excitatory transmitter (Hurwitz et al., 2003), which makes glutamate's role unclear.

RDA exploits the fact that two identified neurons, a tester and a driver, express different complements of mRNA. It uses a subtraction method to reveal mRNAs encoding proteins present only in the neuron of interest, the tester. Previously, we successfully used RDA to identify several neuropeptides (Jing et al., 2010; Romanova et al., 2012). Here we sought to determine whether RDA would also be effective for detecting large proteins, which 
are less abundant than peptides. We studied the interneuron B64 (Hurwitz and Susswein, 1996) and a glutamatergic motoneuron B38 (Fox and Lloyd, 1999). We hypothesized that B64 was glutamatergic because a homologous neuron in the mollusc Lymnaea (Brierley et al., 1997) appears to be glutamatergic based on its pharmacological profile. We performed RDA using B38 and B64 neurons as testers, and identified one clone encoding a protein highly homologous to mammalian VGLUTs. We named the identified molecule Aplysia VGLUT (ApVGLUT).

Vesicular glutamate transporters have been most extensively studied in mammals (El Mestikawy et al., 2011; Omote and Moriyama, 2013). There are three types of mammalian VGLUTs-VGLUT1-3. In invertebrates, there are reports of a single VGLUT in Caenorhabditis elegans, Drosophila, and Lymnaea (Lee et al., 1999; Daniels et al., 2004; Hatakeyama et al., 2010; Serrano-Saiz et al., 2013). Although examination of genomic databases suggests that three types of VGLUT may be present in oyster and Aplysia, presently the expression and functions of the predicted molecules remain to be verified. Indeed, despite the putative identification of VGLUTs in a dozen invertebrates, there is no direct evidence showing that invertebrate VGLUTs actually transport glutamate. Here we show that ApVGLUT indeed functions as a glutamate transporter and that interneuron B64 is ApVGLUT positive. Further, pharmacological data indicate that B64 synaptic potentials are mediated by glutamate. Our combined approaches thus offer an effective means to study actions of transmitters, especially small-molecule transmitters like glutamate, in small circuits. Our study also has implications for understanding the structural and functional evolution of VGLUTs.

\section{Materials and Methods}

Subjects and reagents. Experiments were performed on Aplysia californica (100-250 g) obtained from Marinus. Aplysia are hermaphroditic (i.e., each animal has reproductive organs normally associated with both male and female sexes). Animals were maintained in circulating artificial seawater (ASW) at $14-16^{\circ} \mathrm{C}$. They were anesthetized by injection of $333 \mathrm{~mm}$ isotonic $\mathrm{MgCl}_{2}$ ( $50 \%$ of body weight), and specific ganglia were dissected out and maintained in ASW containing the following (in mM): $460 \mathrm{NaCl}$, $10 \mathrm{KCl}, 55 \mathrm{MgCl}_{2}, 11 \mathrm{CaCl}_{2}$, and 10 HEPES buffer, $\mathrm{pH}$ 7.6, in a dish lined with Sylgard (Dow Corning). All chemicals were purchased from Sigma unless otherwise stated.

\section{RDA procedure}

Recently we modified the RDA approach (Lisitsyn et al., 1993; Hubank and Schatz, 1994) to identify novel peptides from single identified neurons in the Aplysia CNS, as described in detail previously (Jing et al., 2010).

Here we extended the procedure to identify proteins larger than neuropeptides. In brief, the entire procedure can be divided into three steps (Fig. 1): (1) Isolation of two types of identified cells where the first is the cell of interest, or "tester," whose proteins are to be identified. The second cell, or " "driver," is used to subtract sequences that are shared with the tester. The rationale behind this RDA approach is that the tester contains one or more proteins not present in the driver. Multiple cells from each cell type are collected in a solution of ice-cold $50 \%$ propylene glycol and $1.2 \mathrm{M} \mathrm{NaCl}$ in diethylpyrocarbonate-treated $\mathrm{H}_{2} \mathrm{O}$ and stored at $-80^{\circ} \mathrm{C}$. (2) Amplification of the cDNA from the RNA of the tester and the driver is done as described previously (Vilim et al., 2001). (3) RDA (Lisitsyn et al., 1993; Hubank and Schatz, 1994) with the amplified cDNA of the tester and the driver is performed. The cDNAs of the driver and tester were digested with DpnII and the driver cDNA was ligated to R-Bam adaptors, while the tester cDNA was ligated to N-Bam adaptors. DpnII was used to cut cDNA with an average length of 256 bp that contain overhangs to facilitate ligation of adapters for PCR and to clone amplified fragments, because the overhangs are complementary to
BamHI digested plasmids. The driver DNA was amplified with biotinylated R-Bam primer and then hybridized with unamplified tester cDNA. Here, we modified the RDA method by including a physical subtraction based on biotinylated driver primers, streptavidin incubation, and phenol/chloroform extraction (Sive and St John, 1988). This procedure removed the driver and with it any tester CDNA that is complementary and bound to it. We then performed the final amplification with tester $\mathrm{N}$-Bam primer to further enrich the protein sequences that were unique to the tester.

\section{Antibodies}

To generate antibodies, we selected fragments from the $\mathrm{N}$ and $\mathrm{C}$ terminal of ApVGLUT. These regions are less conserved and appear to be cytoplasmic. We bacterially expressed fusion recombinant proteins to $\mathrm{N}$ and $\mathrm{C}$ termini of ApVGLUT. Specifically, $\mathrm{N}$ termini (first 75 aa) and $\mathrm{C}$ termini (last 88 aa) were expressed with 6 Histag in BL21 cells. Proteins were purified using the ion-mobilized affino chromatography method followed by ion exchange chromatography. The purified proteins were used to generate antibodies as previously described (Fujisawa et al., 1999; Furukawa et al., 2001; Li et al., 2001; Sweedler et al., 2002). For each antigen, two male Sprague Dawley rats (250-300 g; Taconic Farms) were immunized by intraperitoneal injections. At days 21 and 42, the rats were boosted by intraperitoneal injections. The animals were killed by decapitation at $49 \mathrm{~d}$, and the blood was harvested and processed for serum. Sera were aliquoted, frozen, and lyophilized or stored at $4^{\circ} \mathrm{C}$ with EDTA $(25$ $\mathrm{mm}$ final concentration) and thimerosal ( $0.1 \%$ final concentration) added as stabilizers. For antibodies that produced immunostaining, specificity was confirmed by pre-incubation of the primary antibodies with the corresponding synthetic protein segment $(100 \mu \mathrm{M})$, which abolished the staining.

\section{Glutamate transport by ApVGLUT in a cell line}

To determine that ApVGLUT in fact transports glutamate, we expressed ApVGLUT in mammalian cell lines, i.e., COS7 cells from monkey kidney. COS7 cells were maintained in DMEM (Life Technologies) supplemented with fetal bovine serum $10 \%$, L-glutamine, $4.5 \mathrm{~g} / \mathrm{L}$ glucose, 0.1 $\mathrm{mg} / \mathrm{L}$ streptomycin, and $100 \mathrm{U} / \mathrm{ml}$ penicillin and incubated at $37^{\circ} \mathrm{C}$ under $5 \% \mathrm{CO}_{2}$ (Hayashi et al., 2001).

Expression of ApVGLUT. ApVGLUT cDNA was subcloned into the HindIII and XbaI sites of expression vector pc DNA 3 (Invitrogen). To amplify DNA we designed primers with restriction sites (HindIII, XbaI) on the ends. The sense primer was as follows: 5' CCC AAG CTT ATG CCT TTT GGT GCG TTT AAT AAC. The antisense primer was as follows: 5' GGG TCT AGA CTA GAA GTC TTT CTC GCT GTC GTC. The resultant construct ApVGLUT-pcDNA3 was used to transfect COS7 cells using Effectene Transfection Reagent (Qiagen).

$R T-P C R$. Total RNA was isolated from cells grown in $100 \%$ confluent dishes $(10 \mathrm{~cm})$. Cells were washed with PBS $\left(20 \mathrm{mM} \mathrm{Na}_{2} \mathrm{HPO}_{4}\right.$ and 150 $\mathrm{mm} \mathrm{NaCl}, \mathrm{pH} 7.2$ ) and then scraped in $4 \mathrm{ml}$ of PBS. They were then centrifuged at $3000 \mathrm{rpm}$ and resuspended in $200 \mu \mathrm{l}$ of PBS. For isolation, we used a total RNA Pure RNA kit (Boehringer Mannheim; the current name is High Pure RNA Isolation Kit from Roche). Total RNA was transcribed into cDNA by RT Superscript II (Invitrogen) in a final volume of $20 \mu \mathrm{l}$. After $2 \mathrm{~h}$ at $42^{\circ} \mathrm{C}$, the reaction was terminated by heating at $70^{\circ} \mathrm{C}$ for $30 \mathrm{~min}$. For PCR amplification, 10-fold diluted synthesized cDNA was added to the reaction buffer with dNTPs and specific primers for ApVGLUT. Thirty-five cycles were conducted.

Immunohistochemistry (cultured cells). Microscope cover glass (Fisher) was used in 12-well plates. Cells were plated with a density of $2 \times 10^{4}$ and grown overnight at $37^{\circ} \mathrm{C}$. Cells were washed with PBS and fixed in $4 \%$ paraformaldehyde/PBS solution for $40 \mathrm{~min}$ at room temperature. They were then washed with PBS for $3 \times 10$ min and permeabilized with $0.1 \%$ Triton in the same buffer for $40 \mathrm{~min}$, followed by incubation in a blocking solution ( $2 \%$ normal goat serum and $0.5 \%$ BSA) for $1 \mathrm{~h}$. Incubation with primary antibody against ApVGLUT (1:100 or 1:1000) was performed overnight at $4^{\circ} \mathrm{C}$. Cells were washed with a slow rocking motion for $3 \times 15$ min with the same blocking solution, then incubated with a secondary goat anti-rat rhodamine antibody (1:1000 or 1:2000) for $2 \mathrm{~h}$, and again washed for $3 \times 15 \mathrm{~min}$. Immunoreactivity was examined under a Nikon fluorescence microscope. 
Measurement of glutamate transport. For the permeabilization assay, COS7 cells were plated on $35 \mathrm{~mm}$ dishes coated with poly-L-lysine with a density of $2.0 \times 10^{5}$ cells per dish and cultured overnight at $37^{\circ} \mathrm{C}$. The next day cells were transfected with $2 \mu \mathrm{g}$ construct ApVGLUT-pcDNA3 per dish.

We measured the COS7 cells' uptake of the radioactively labeled glutamate following digitonin permeabilization of the plasma membrane as previously described (Hayashi et al., 2001). Briefly, after further incubation with ApVGLUT-pcDNA3 for $48 \mathrm{~h}$, ApVGLUT-expressing COS7 cells were rinsed with $1 \mathrm{ml}$ of buffer comprising $20 \mathrm{~mm}$ MOPS-Tris, $\mathrm{pH}$ 7.0; $0.3 \mathrm{~m}$ sucrose; $2 \mathrm{~mm}$ magnesium acetate; and $4 \mathrm{~mm} \mathrm{KCl} \mathrm{twice.} \mathrm{The}$ cells were then permeabilized for $10 \mathrm{~min}$ at $37^{\circ} \mathrm{C}$ in $0.5 \mathrm{ml}$ of the same buffer containing $10 \mu \mathrm{M}$ digitonin. The medium was then replaced with fresh buffer containing Tris-ATP at $2 \mathrm{~mm}$ in the absence of digitonin. In some experiments, Evans blue, FCCP, bafilomycin A1, nonradioactive glutamate, or L-/D-aspartate was also included in the medium at the specified concentrations. Glutamate uptake was immediately started by the addition of radioactive L-glutamate $(2.5 \mu \mathrm{Ci}, 0.1 \mathrm{~mm})$ at $37^{\circ} \mathrm{C}$. After a $10 \mathrm{~min}$ incubation, uptake was terminated by washing the cells with $1 \mathrm{ml}$ of ice-cold $20 \mathrm{~mm}$ MOPS-Tris, pH 7.0, containing $0.3 \mathrm{~m}$ sucrose. Cells were lysed with $1 \mathrm{ml}$ of $1 \%$ SDS and the radioactivity and protein concentration were measured. Glutamate uptake was measured as $\mathrm{cpm} / \mu \mathrm{g}$ protein and normalized to the cells expressing ApVGLUT.

\section{In situ hybridization}

In situ hybridization (ISH) was performed as described previously (Vilim et al., 2001; Jing et al., 2010). Ganglia were digested with 1\% protease type IX (Sigma-Aldrich) in $10 \mathrm{ml}$ of ASW for $3 \mathrm{~h}$ at room temperature (with rocking) to facilitate the removal of the sheath. After digestion, ganglia were washed with ASW and fixed overnight at $4^{\circ} \mathrm{C}$ with $4 \%$ paraformaldehyde (Electron Microscopy Sciences) in PBS. Ganglia were then washed, desheathed, and dehydrated in an ascending ethanol series. After rehydration in a descending ethanol series, ganglia were prehybridized for $6 \mathrm{~h}$ and then hybridized overnight at $50^{\circ} \mathrm{C}$ in hybridization buffer (50\% formamide, 5 mM EDTA, $5 \times$ SSC, $1 \times$ Denhardt's solution, $0.1 \%$ Tween 20 , and $0.5 \mathrm{mg} / \mathrm{ml}$ yeast tRNA) containing $2 \mu \mathrm{g} / \mathrm{ml}$ digoxigeninlabeled cRNA probes made from ApVGLUT cDNA templates. After washout of the probes, ganglia were then incubated overnight at $4^{\circ} \mathrm{C}$ with a 1:200 dilution of alkaline phosphatase-conjugated anti-digoxigenin antibody (Roche Molecular Biochemicals) in PBS containing 0.1\% Tween 20 (PBT), 0.2\% BSA (catalog \#A0281; Sigma-Aldrich), and 1\% normal goat serum. After washes with PBT to remove unbound antibody, ganglia were washed with detection buffer (100 mM NaCl, $50 \mathrm{~mm} \mathrm{MgCl}_{2}, 0.1 \%$ Tween 20, $1 \mathrm{~mm}$ levamisol, and $100 \mathrm{~mm}$ Tris-HCl, pH 9.5) and developed with $4.5 \mu$ lof nitro blue tetrazolium and $3.5 \mu$ l of 5-bromo-4-chloro-3indolyl phosphate (Roche Molecular Biochemicals) in $1 \mathrm{ml}$ of detection buffer. The staining reaction was monitored visually and stopped by washing with PBT when the level of staining was adequate. The stained ganglia were observed and photographed using a fluorescence microscope (Nikon) with epi-illumination against a white background. Photographs were taken with a Nikon Coolpix 990 digital camera, imported into Photoshop, and compiled into figures.

Double labeling of dye-injected B64 interneurons with ISH was performed as above with slight modifications to fluorescently label ApVGLUT mRNA. B64 was physiologically identified and injected with carboxyfluorescein (Jing et al., 2003). The ganglia were hybridized with the same cRNA probe as above. After wash, ganglia were incubated overnight at $4^{\circ} \mathrm{C}$ with a 1:200 dilution of anti-digoxigenin-rhodamine, Fab fragments (Roche) in PBT, $0.2 \%$ BSA, and $1 \%$ normal goat serum. Ganglia were then washed with PBS. The preparations were viewed and photographed with a confocal microscope.

\section{Immunocytochemistry}

Immunocytochemistry (whole mount) was performed as described previously (Furukawa et al., 2001; Jing et al., 2007). Central ganglia were fixed in $4 \%$ paraformaldehyde, $0.2 \%$ picric acid, $25 \%$ sucrose, and $0.1 \mathrm{M}$ $\mathrm{NaH}_{2} \mathrm{PO}_{4}, \mathrm{pH} 7.6$, for either $3 \mathrm{~h}$ at room temperature or overnight at $4^{\circ} \mathrm{C}$. After washes with PBS, ganglia were desheathed to expose the neurons, except in ganglia from small animals $(10-15 \mathrm{~g})$. All subsequent incuba- tions were done at room temperature. Tissue was permeabilized and blocked by overnight incubation in blocking buffer (10\% normal goat serum, 2\% Triton X-100, 1\% BSA, $154 \mathrm{~mm} \mathrm{NaCl}, 50$ mm EDTA, 0.01\% thimerosal, and $10 \mathrm{~mm} \mathrm{Na}_{2} \mathrm{HPO}_{4}, \mathrm{pH}$ 7.4). The primary antibody was diluted 1:250 in blocking buffer and incubated with the tissue for 4-7 d. The tissue was then washed twice per day for 2-3 d with washing buffer ( $2 \%$ Triton X-100, 1\% BSA, $154 \mathrm{~mm} \mathrm{NaCl}, 50$ mm EDTA, 0.01\% thimerosal, and $10 \mathrm{~mm} \mathrm{Na}_{2} \mathrm{HPO}_{4}$, $\mathrm{pH}$ 7.4). It was then incubated with a 1:500 dilution of secondary antibody (lissamine rhodamine goat anti-rat; Jackson ImmunoResearch) for 2-3 d. The tissue was then washed twice with washing buffer for $1 \mathrm{~d}$ and four times with storage buffer (1\% BSA, 154 $\mathrm{mm} \mathrm{NaCl}, 50$ mм EDTA, 0.01\% thimerosal, and $10 \mathrm{~mm} \mathrm{Na}_{2} \mathrm{HPO}_{4}, \mathrm{pH}$ 7.4) for $1 \mathrm{~d}$.

For double labeling of physiologically identified B64 cells with ApVGLUT, neurons were identified based on morphology and electrophysiological characters and injected with carboxyfluorescein. Tissue was fixed and processed for immunocytochemistry as described above.

\section{Western blot}

Western blot was performed with equal amounts of protein from buccal, cerebral, pleural, pedal, and abdominal ganglia, and $50 \mu \mathrm{g}$ of protein was loaded per lane. The concentration of protein was measured using a Bradford assay in loading buffer before phenol blue was applied.

\section{Electrophysiology}

Electrophysiological recordings from CNS preparations (including the cerebral and buccal ganglia) were performed as described previously (Jing and Weiss, 2005; Bai et al., 2013; Wu et al., 2014). Ganglia were desheathed, transferred to a recording chamber containing $1.5 \mathrm{ml}$ of ASW, continuously perfused at $0.3 \mathrm{ml} / \mathrm{min}$, and maintained at $14-17^{\circ} \mathrm{C}$. To suppress polysynaptic pathways, a high divalent cation saline was used containing the following (in mM): $368 \mathrm{NaCl}, 10 \mathrm{KCl}, 13.8 \mathrm{CaCl}_{2}, 101$ $\mathrm{MgCl}_{2}$, and 10 HEPES, $\mathrm{pH}$ 7.6. This high-divalent cation saline was used here because it did not alter the amplitudes of PSPs (Trudeau and Castellucci, 1992). It has lower divalent ionic concentration than highdivalent saline commonly used in other studies (Byrne et al., 1978). Drugs were dissolved in ASW immediately before each application. The ASW with the drug was perfused into the recording chamber, except for the glutamate puff, which was applied to the cell of interest with broken electrodes of 3-5 $\mu \mathrm{m}$ diameter through pressure ejection (Picospritzer II; General Valve ). During all pharmacological experiments, we made sure that the membrane potential during the drug perfusion remained the same as the control by applying appropriate hyperpolarization or depolarization currents. The cell hyperpolarization/depolarization was performed using single electrode current-clamp technique and care was taken to correctly balance the electrode resistance.

Intracellular recordings were made using single-barrel electrodes (5$10 \mathrm{M} \Omega$ ) filled with either $2 \mathrm{M} \mathrm{K}$-acetate and $30 \mathrm{~mm} \mathrm{KCl}$ or $0.6 \mathrm{M} \mathrm{K}_{2} \mathrm{SO}_{4}$ and $60 \mathrm{~mm} \mathrm{KCl}$. Intracellular signals were acquired using an Axoclamp 2B or 900A amplifier (Molecular Devices), Neuroprobe amplifier Model 1600 (A-M Systems), or a Getting model 5A amplifier. A Grass model S88 stimulator was used for stimulation.

\section{Data analysis}

Electrophysiological recordings were digitized on-line with AxoScope (Molecular Devices) and plotted with CorelDraw (Corel). Bar graphs were plotted using SigmaPlot. Data are expressed as the mean \pm SEM. Statistical tests included a Student's $t$ test and a repeated-measures oneway ANOVA and were applied as appropriate using Prism software (GraphPad). Data that showed significant effects in ANOVA were further analyzed in individual comparisons with Bonferroni's correction. In all statistical tests, effects were considered statistically significant when $p<0.05$.

\section{Results}

\section{Identification of Aplysia vesicular glutamate transporter by RDA}

In this study, we sought to extend the utility of the RDA method to identify a protein in glutamatergic neurons in the feeding cir- 
cuit. To accomplish this, we used the putative glutamatergic motoneuron B38 (Fox and Lloyd, 1999) as a tester and B1/B2 as a driver (Fig. 1). The conventional neurotransmitter of $\mathrm{B} 1$ is presently unknown, whereas B2 is known to be cholinergic (Lloyd et al., 1985). Our goal was to clone the RNAs that may be specifically expressed in B38.

The first round of subtraction between B38 and B1/B2 allowed abundant RNAs present in B38 to be apparent as prominent difference bands, i.e., between 0.5 and $0.75 \mathrm{~kb}$ (Fig. 1). Subcloning the products of the first subtraction did not yield useful colonies that contained unique products (as determined by differential screening; perhaps due to the smear of products contained in all the lanes). To reduce the number of products and enhance difference bands we performed a second round of subtraction by repeating step 3 (Fig. 1), i.e., the driver cDNAs were digested with DpnII and ligated with the driver CDNA and then PCR amplified using biotinylated primers and hybridized with products from the first subtraction. Subcloning the products from this second subtraction produced colonies that contained unique products (as determined by differential screening). Several difference clones obtained from B38 were sequenced to reveal open reading frames that code for proteins; one of them is described in detail in this report.

We also performed similar experiments with the interneuron B64, a putative glutamatergic cell. For this RDA we only performed one round of subtraction and did not have to perform a second round of subtraction, as we did for B38. Importantly, one difference clone obtained from B64 with RDA matched one of the clones obtained from B38. Its sequence has been deposited into the NCBI database (GenBank accession number: KR697562).

To identify the protein present in both B64 and B38, we performed a Blast search (Table 1). We found that it has high homology to known vesicular glutamate transporters. Therefore we named it Aplysia vesicular glutamate transporter or ApVGLUT.

\section{Bioinformatics of ApVGLUT}

We performed a bioinformatics analysis to determine the relationship between ApVGLUT and other proteins. First, we compared ApVGLUT to an Aplysia glutamate transporter described in a previous study, ApGT1 (Levenson et al., 2000; Collado et al., 2007). Because these authors

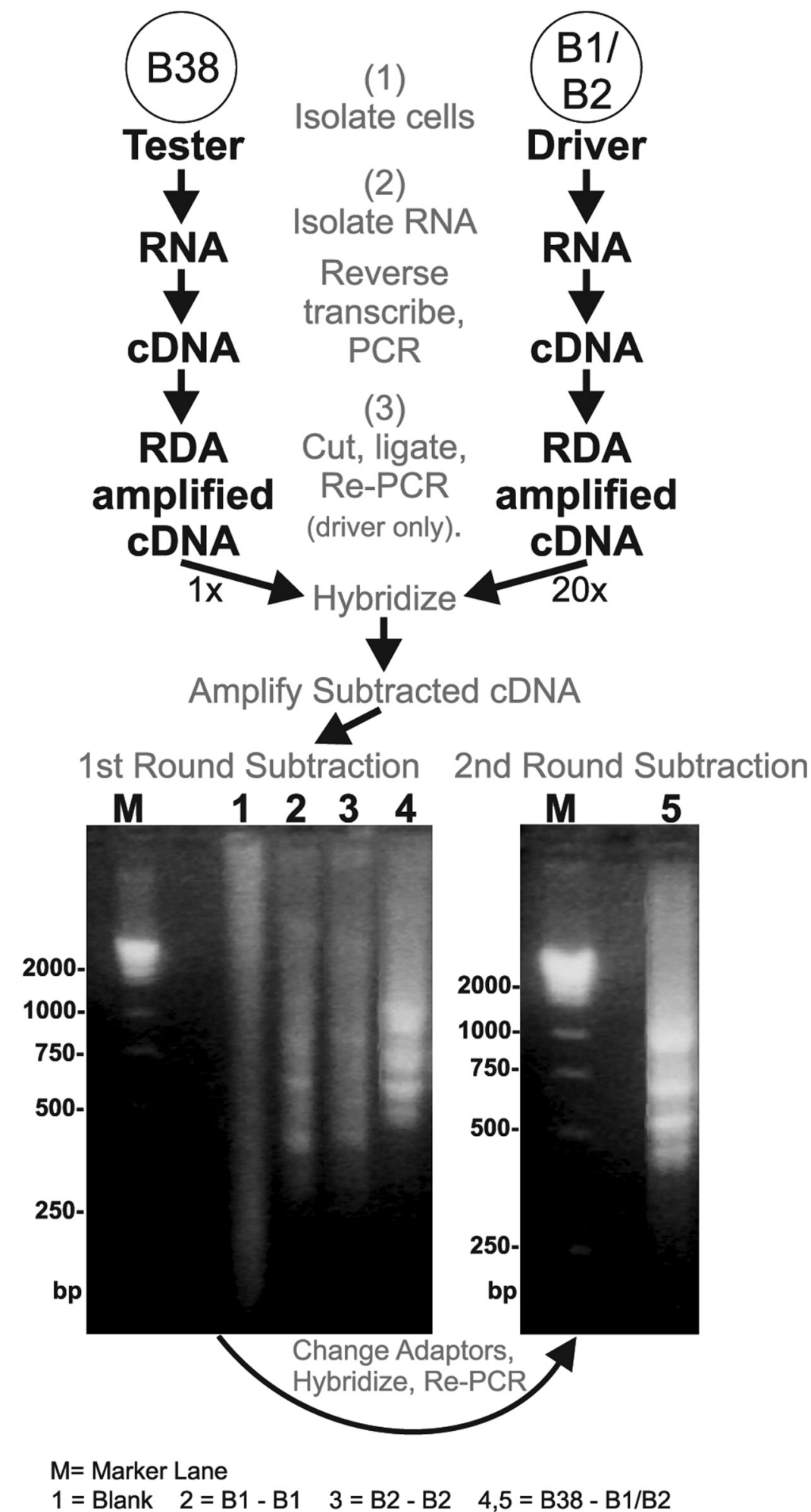

Figure 1. RDA procedure used to identify ApVGLUT. Illustrated is the RDA between a glutamatergic neuron, $B 38$, and B1/B2 neurons. The results of the subtractions performed are shown in the gels at the bottom. Bottom left, The results of the first subtraction performed. Lane 1 is a blank subtraction. Lanes 2 and 3 are additional control subtractions using the B1 or B2 neurons subtracted against themselves, respectively. These lanes only show a weak smear with some faint bands. Lane 4 is a B38 that was subtracted against neurons $B 1$ and $B 2$. This lane shows some intense bands that do not appear in the control subtractions. $M$, Marker lane showing cDNA masses in base pairs. Bottom right, Lane 5 shows the results of a second round of subtraction. Among several clones, one difference clone obtained from B38 was sequenced to reveal an open reading frame that coded for a protein named ApVGLUT. 
Table 1. List of VGLUTs used for bioinformatics analysis

\begin{tabular}{|c|c|c|c|}
\hline VGLUTS & $\begin{array}{l}\text { Sequence } \\
\text { similarities }\end{array}$ & Full names & GenBank ID \\
\hline LsVGLUT-622 & $87.5 \%$ & VGLUT, Lymnaea stagnalis & BAG83236.1 \\
\hline AvVGLUT-609 & $82.8 \%$ & VGLUT, Ambigolimax valentianus & BAG41985.1 \\
\hline CgVGLUT2.1-618 & $67.8 \%$ & VGLUT2.1, Crassostrea gigas & EKC24439.1 \\
\hline MmVGLUT2-582 & $64.8 \%$ & VGLUT2, Mus musculus & NP_543129.3 \\
\hline ClfSCF17m6-583 & $64.5 \%$ & $\begin{array}{l}\text { SCF17m6(VGLUT2), Canis /upus } \\
\text { familiaris }\end{array}$ & EDM07210.1 \\
\hline BtVGLUT2-582 & $64.2 \%$ & VGLUT2, Bos Taurus & NP_001096580.1 \\
\hline HsVGLUT2-582 & $64.2 \%$ & VGLUT2, Homo sapiens & NP_065079.1 \\
\hline HsVGLUT3i1-589 & $63.9 \%$ & VGLUT3 isoform $1, H$. sapiens & NP_647480.1 \\
\hline DrVGLUT3-590 & $63.5 \%$ & VGLUT3, Danio rerio & ACG50690.1 \\
\hline MmVGLUT3-601 & $63.3 \%$ & VGLUT3, M. musculus & NP_892004.1 \\
\hline DrVGLUT2.2-587 & $62.4 \%$ & VGLUT2.2, D. rerio & NP_001009982.1 \\
\hline DrVGLUT2.1-584 & $61.1 \%$ & VGLUT2.1, D. rerio & BAD67437.1 \\
\hline MmVGLUT1-560 & $60.5 \%$ & VGLUT1, M. musculus & NP_892038.2 \\
\hline HsVGLUT1-560 & $60.5 \%$ & VGLUT1, H. sapiens & NP_064705.1 \\
\hline DrVGLUT1-582 & $59.6 \%$ & VGLUT1, D. rerio & NP_001092225.1 \\
\hline HsVGLUT3i2-539 & $56.8 \%$ & VGLUT3 isoform 2, H. sapiens & NP_001138760.1 \\
\hline CeEAT4i1-576 & $55.7 \%$ & $\begin{array}{l}\text { Protein EAT-4 isoform a, } \\
\text { Caenorhabditis elegans }\end{array}$ & CAA80150.1 \\
\hline CeEAT4i2-555 & $54.6 \%$ & $\begin{array}{l}\text { Protein EAT- } 4 \text { isoform b, } \\
\text { C. elegans }\end{array}$ & CCW46023.1 \\
\hline DmVGLUT-632 & $52.8 \%$ & VGLUT, Drosophila melanogaster & AAF51256.2 \\
\hline
\end{tabular}

did not deposit their sequence into the NCBI database, we copied it from their paper and found an identical sequence predicted by the Aplysia Genome Project (http://www.broadinstitute.org/science/projects/mammals-models/vertebrates-invertebrates/aplysia/aplysia-genome-sequencing-project). The sequence from the Aplysia Genome Project was named Aplysia californica excitatory amino acid transporter 2 like (accession number: XP_005103093). This protein belongs to a separate class of glutamate transporters that are localized to the cell membrane. It has little homology to ApVGLUT and, thus, is not directly related to it.

In addition to the sequence for the cell membrane transporter, the Aplysia Genome Project predicts six vesicular glutamate transporter sequences (accession number: XP_005108654.1, XP_005108649.1,XP_005105900.1,XP_005104627.1,XP_005095393.1, and XP_005090726.1). Based on sequence alignment (BioEdit software; http://www.mbio.ncsu.edu/BioEdit/bioedit.html), our sequence is most similar to the third sequence (vesicular glutamate transporter-3 like, 128 aa; identity with our sequence: $20.5 \%)$. If we remove the nonoverlapping sequence from ApVGLUT, the identity became $97.7 \%$, raising the possibility that the third sequence is a fragment of ApVGLUT. Importantly, most of these sequences are short $(<391 \mathrm{aa})$. The only exception is the first sequence, which is 505 aa. Complete vesicular glutamate transporters are usually larger than 560 aa. Thus, the six predicted sequences are likely to be incomplete, precluding a more meaningful comparison with ApVGLUT (611 aa).

Finally, we used "tblastn" to search a transcriptome database (http://www.aplysiagenetools.org/) of various Aplysia tissues (including the CNS). This database is yet to be deposited in the NCBI database. We found four identical sequences (e.g., c127598_g2_i1, 584 aa) that have an identity score of 95\% with our sequence. The only difference between ApVGLUT and the four sequences is that the latter are missing two stretches of amino acids (271-284 and 393-404). Interestingly, we did not find any other sequences that were as long as ours (i.e., >500 aa). Nevertheless, the search verifies the presence of our sequence in the Aplysia transcriptome.
Second, we sought to determine how similar ApVGLUT is to proteins in other species. To identify proteins for comparison we performed a Blast search, which yielded 100 related sequences. All 100 sequences were labeled as vesicular glutamate transporters with a majority of them being "Predicted." The large number of sequences made it difficult to perform a meaningful comparison with ApVGLUT. We therefore sought to compile a more manageable list (Table 1), first by excluding the Predicted sequences that appeared to be solely derived from genome projects and are by and large unconfirmed. This left nine sequences: Lymnaea (LsVGLUT-622), Greenhouse slug (AvVGLUT-609), Oyster (CgVGLUT2.1618), Rat (RnSCF17m6-588 and RnVGLUT2-582), Mouse (MmVGLUT2-582), Cattle (BtVGLUT2-582), Dog (ClfSCF17m6583), and Human (HsVGLUT2-582). We decided to keep one rodent species (i.e., MmVGLUT2-582) and excluded both RnSCF17m6-588 and RnVGLUT2-582.

Mammalian VGLUTs are the best studied, and have been shown to be of three major types, i.e., VGLUT1, VGLUT2, VGLUT3, which may differ in terms of their distribution and function (El Mestikawy et al., 2011; Omote and Moriyama, 2013). We therefore wanted to compare ApVGLUT to all three mammalian VGLUTs. Our Blast search only returned VGLUT2s. We therefore added VGLUT1s and VGLUT3s from several mammalian species (HsVGLUT1-560, MmVGLUT1-560, HsVGLUT3i1589, HsVGLUT3i2-539, and MmVGLUT3-601). A further goal of this work was to determine how VGLUTs might evolve (cf. Moroz et al., 2006; Sossin and Abrams, 2009; Hatakeyama et al., 2010; Lin et al., 2010). Consequently, we added sequences from several model systems along the evolutionary tree: $C$. elegans (CeEAT4i1-576 and CeEAT4i2-555), Drosophila (DmVGLUT632), zebrafish (DrVGLUT1-582, DrVGLUT2.1-584, DrVGLUT2.2587, and DrVGLUT3-590; Higashijima et al., 2004; Obholzer et al., 2008). This resulted in a total of 19 sequences in our list.

We used BioEdit software (http://www.mbio.ncsu.edu/ BioEdit/bioedit.html) with a BLOSUM62 matrix algorithm to analyze the similarities between ApVGLUT and the 19 sequences. Table 1 shows the results and indicates that ApVGLUT is most similar to Lymnaea VGLUT with a similarity score of $87.5 \%$. The second and third sequences in the list were also obtained from molluscs. Following the three molluscan sequences are VGLUT2s from mammals, including Bos taurus (cattle), Canis (dog), humans, rat, and mice. Thus, these data suggest that, outside of molluscs, ApVGLUT is most similar to mammalian VGLUTs, particularly VGLUT2s.

To examine the possible transmembrane domain structure of ApVGLUT, we generated a hydrophobicity plot (Fig. 2A) with the BioEdit software. This plot is typical of vesicular transporter proteins with multiple transmembrane domains. It suggested that ApVGLUT may have eight transmembrane domains, i.e., there are eight regions with a hydrophobicity that is $>1$.6. It also indicated that the $\mathrm{N}$ and $\mathrm{C}$ terminus of the molecule are likely to be cytoplasmic. We also used TMHMM software (http://www. cbs.dtu.dk/services/TMHMM/) to predict helical transmembrane regions (Table 2). This analysis suggested that there might be 10 helical transmembrane regions in ApVGLUT. Similar results were obtained with two other software packages (TMPred 1 and WHAT), which predicted 9-10 helical transmembrane regions.

Sequence alignment between ApVGLUT and other mammalian VGLUTs showed that most similarities were observed in the middle of the protein. Proteins differed significantly at the two ends (1-81 and 540-611 aa; Fig. 2B). This suggests 
A

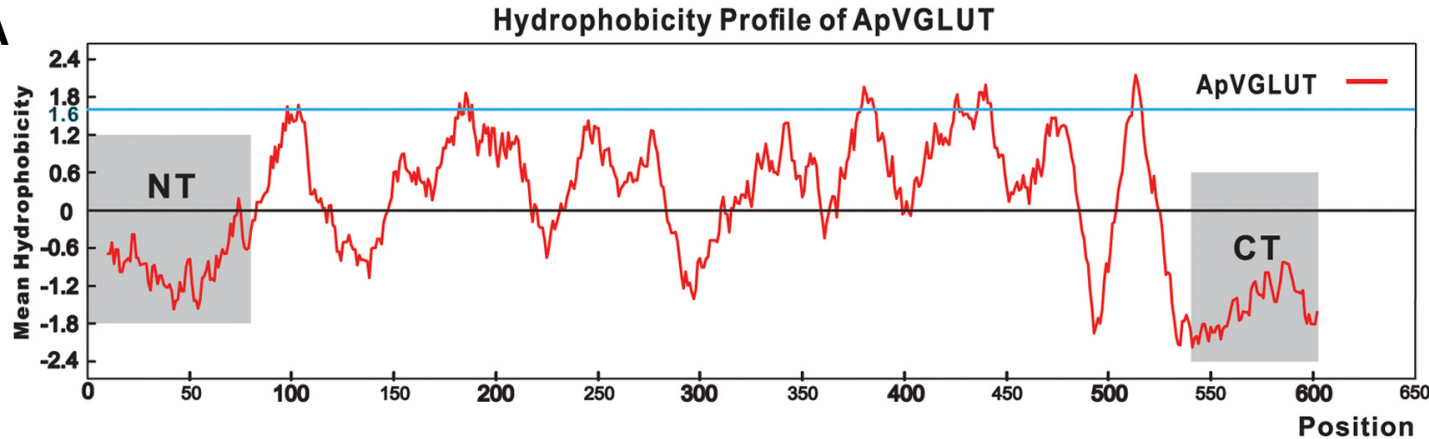

B

Hydrophobicity Profiles of ApVGLUT and MmVGLUTs

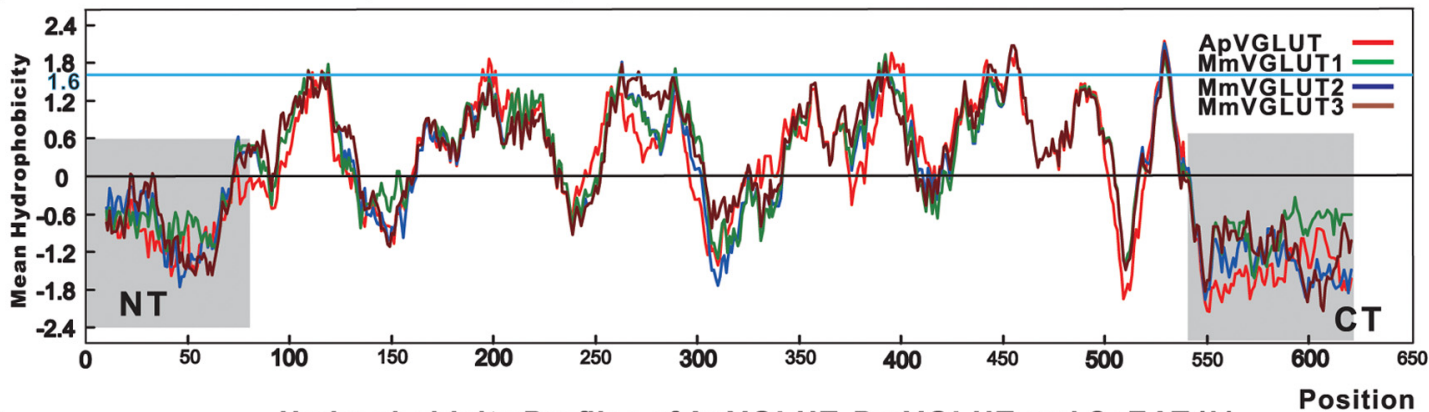

C

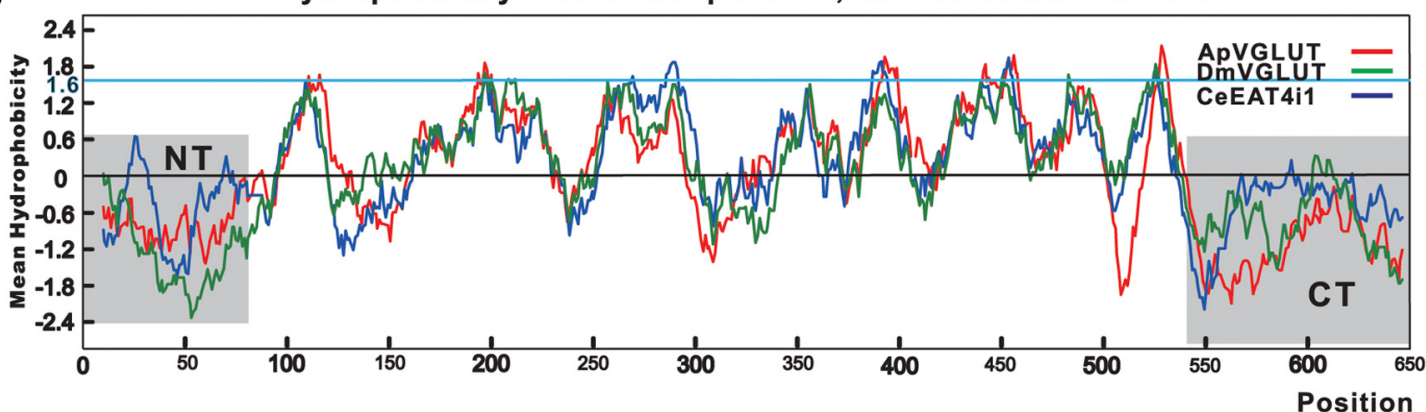

Figure 2. Hydrophobicity profile of ApVGLUT and a comparison with hydrophobicity plots of mice VGLUT1-3s and Drosophila and C. elegans VGLUTs. Kyte-Doolittle hydrophobicity plots were made by BioEdit software (window size $=19$ ). $A$, The hydrophobicity profile of ApVGLUT is typical of transporter proteins with multiple transmembrane domains. N-terminal (NT) and C-terminal (CT) domains are hydrophilic and are likely to be cytoplasmic. $\boldsymbol{B}, \boldsymbol{C}$, The hydrophobicity profile of ApVGLUT is overlaid with those of mice VGLUTs (B) or Drosophila and C. elegans VGLUTs (C). The plots were drawn after multiple sequence alignments using BioEdit software. They show that the likely transmembrane regions of ApVGLUT are similar to those of mice VGLUTs and Drosophila and $C$. elegans VGLUTs (although there appears to be more differences between ApVGLUT and Drosophila and C. elegans VGLUTs than between ApVGLUT and mice VGLUTs). In contrast, the NT and CT regions showed large variability between ApVGLUT and all other VGLUTs. NT sequence: 1-80; CT sequence: 540 - end.

Table 2. Prediction of helical membrane regions using TMHMM

\begin{tabular}{|c|c|c|c|c|c|c|c|}
\hline Sequence & $1-88$ & $89-111$ & $112-146$ & $147-169$ & $170-175$ & $176-195$ & $196-236$ \\
\hline Region & i1 & M1 & 01 & M2 & $i 2$ & M3 & 02 \\
\hline Sequence & $237-259$ & $260-265$ & $266-285$ & $286-370$ & $371-393$ & $394-405$ & $406-425$ \\
\hline Region & M4 & i3 & M5 & 03 & M6 & i4 & M7 \\
\hline Sequence & $426-428$ & $429-451$ & $452-463$ & $464-486$ & $487-500$ & $501-523$ & $524-611$ \\
\hline Region & 04 & M8 & i5 & M9 & 05 & M10 & i6 \\
\hline
\end{tabular}

I, inside region; $M$, membrane helix; 0,outside region.

that transmembrane regions are more conserved with large variability present at $\mathrm{N}$ and $\mathrm{C}$ termini. For comparison, we generated hydrophobicity plots for mice VGLUT1-3 and Drosophila and C. elegans VGLUTs, and overlaid the ApVGLUT hydrophobicity plot with them (Fig. $2 B, C$ ). This comparison showed that the hydrophobicity plot of ApVGLUT is largely similar to those of mice VGLUT1-3 and Drosophila and $C$. elegans VGLUTs, suggesting that the basic structure (e.g., transmembrane domains of ApVGLUT) is similar to other VGLUTs, although there appears to be more differences between ApVGLUT and Drosophila and C. elegans VGLUTs than between ApVGLUT and mice VGLUTs.
With the 19 sequences and ApVGLUT, we used MEGA software (https://mega.co.nz/) to generate a phylogenetic tree (Fig. 3). As expected this analysis indicated that ApVGLUT is closest to the Lymnaea VGLUT. It further suggested that ApVGLUT is more similar to mammalian VGLUTs than to Drosophila or C. elegans VGLUTs.

\section{ApVGLUT transports glutamate}

The structural similarity between ApVGLUT and other vesicular glutamate transporters suggests that ApVGLUT is indeed a glutamate transporter. To verify this, we expressed ApVGLUT in COS7 cell lines and examined the cells' uptake of radioactively labeled glu- 


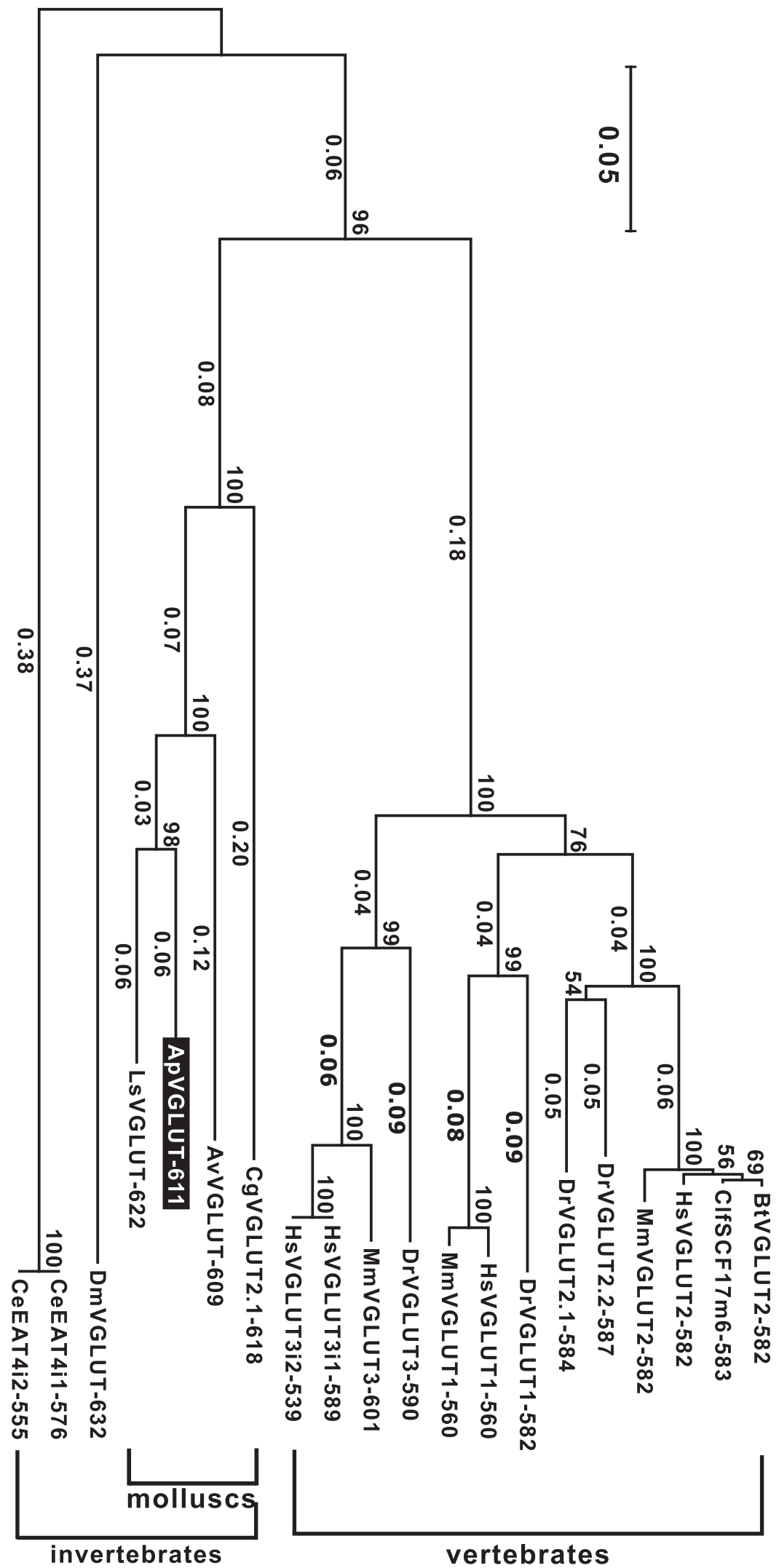

Figure 3. Phylogenic tree resulting from the analysis of the 19 selected proteins (Table 1) that are related to ApVGLUT. Numbers on the nodes show the bootstrap scores (percentage) out of 1000. The scale bar indicates the number of substitutions per site. ApVGLUT is most closely related to molluscan VGLUTs, e.g., LsVGLUT. Notably, outside of molluscs, ApVGLUT is more closely related to mammalian VGLUTs (distance between ApVGLUT and mammalian VGLUT2s is 0.53) than to homologous proteins in two other invertebrates: C. elegans (distance from ApVGLUT: 0.755) and Drosophila (distance from ApVGLUT: 0.733). tamate following digitonin permeabilization of the plasma membrane (Hayashi et al., 2001).

We verified successful expression of ApVGLUT mRNA in COS7 cells using RT-PCR (Fig. 4A) and immunocytochemistry (Fig. $4 B)$. To make antibodies more specific, we selected fragments from the $\mathrm{N}$-terminal and C-terminal portions of ApVGLUT (regions that showed the most variability in our sequence comparisons). We bacterially expressed the two fragments, $\mathrm{N}$ termini (75 aa) and $\mathrm{C}$ termini (88 aa; with 6 Histag in BL21 cells), and then used the purified products as antigens to immunize rats to produce two antibodies ( $\mathrm{N}$ termini, iNT, and $\mathrm{C}$ termini, $\mathrm{iCT}$ ).

The immunostaining in COS7 cells (Fig. 4B2) was cytoplasmic and had a punctate appearance, suggesting that it was localized to intracellular organelles that take up glutamate. This is consistent with an earlier study (Hayashi et al., 2001), which reported punctate staining when mammalian VGLUT2 was expressed in COS7 cells and was presumably localized to endosomes.

Glutamate uptake in COS7 cells transfected with ApVGLUT was significantly higher than glutamate transport in cells that had been transfected with the vector alone $(n=5$; Fig. $4 C)$. ATP is required to maintain the proton gradient that enables uptake of glutamate into vesicles (Roseth et al., 1995; Bellocchio et al., 2000; Hayashi et al., 2001). Consistent with this, omitting ATP reduced glutamate retention by COS7 cells transfected with ApVGLUT $(n=5)$. In addition, we disrupted the proton gradient pharmacologically with a proton ionophore, FCCP $(40 \mu \mathrm{M}$, $n=4$ ), and with bafilomycin Al (a specific inhibitor of vacuolar proton ATPase; Hayashi et al., 2001; $1 \mu \mathrm{M}, n=3$ ). These treatments reduced glutamate retention. Evans blue is an effective inhibitor of mammalian VGLUT (Roseth et al., 1995; Bellocchio et al., 2000) and at $5 \mu \mathrm{M}$ reduced glutamate uptake in COS7 cells transfected with ApVGLUT $(n=3)$. Finally, $1 \mathrm{~mm}$ nonradioactive glutamate competitively reduced uptake of radioactive glutamate $(n=6)$, whereas $1 \mathrm{~mm}$ L-aspartate $(n=4)$ and $1 \mathrm{~mm}$ D-aspartate $(n=3)$ had no effect. These results indicate that ApVGLUT is in fact a proton gradientdependent glutamate transporter.

\section{ApVGLUT expression in Aplysia CNS} and B64 interneurons

To determine the distribution of ApVGLUT in the Aplysia CNS, we first performed ISH experiments with a digoxigeninlabeled antisense-RNA probe. ISH staining 

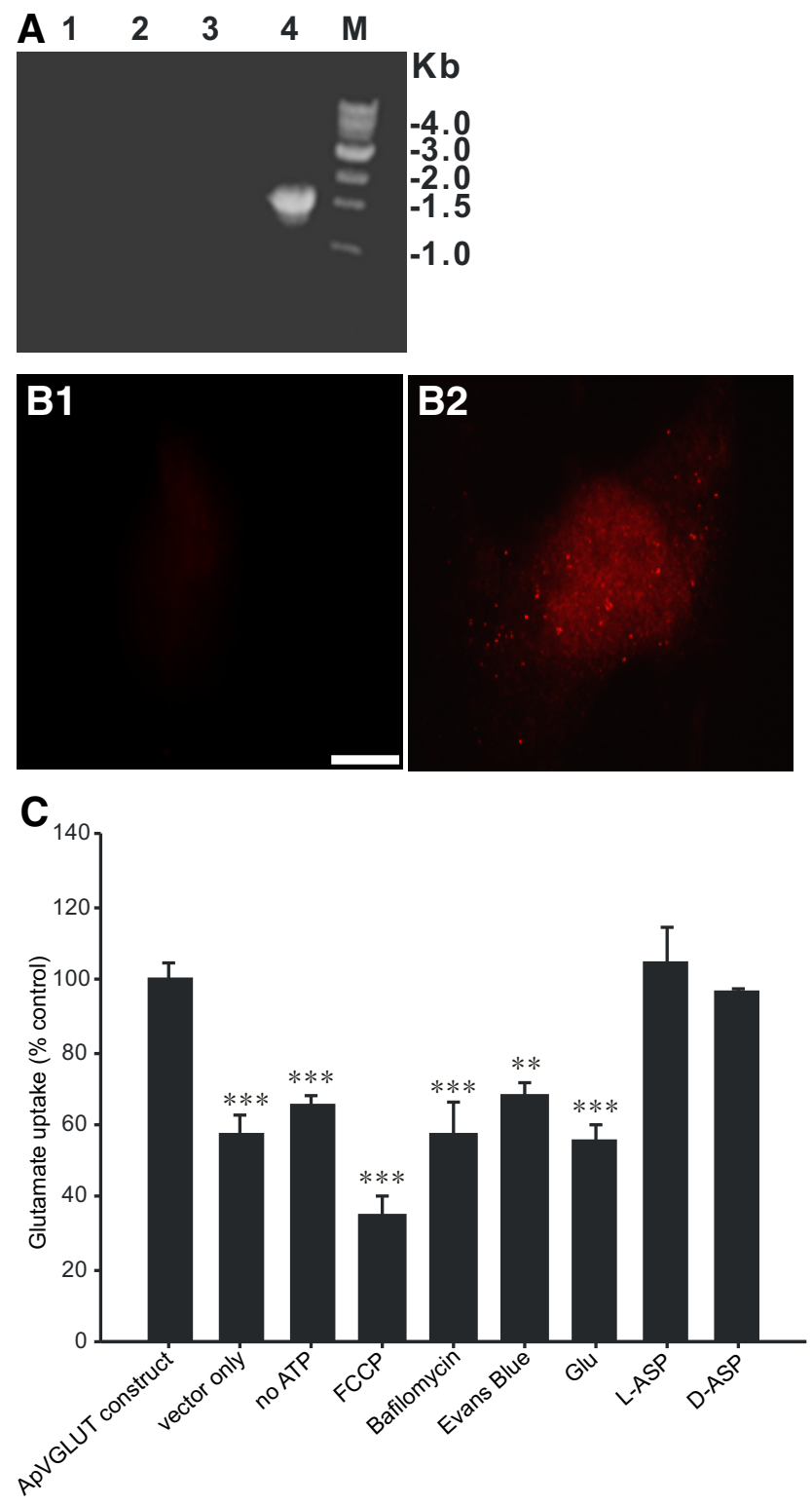

Figure 4. Glutamate transport by ApVGLUT expressed in COS7 cells. $\boldsymbol{A}, \boldsymbol{B}$, Verification of ApVGLUT expression in COS7 cells. A, RT-PCR detection of gene expression of ApVGLUT in a stable line of COS7 cells (clone 7-1 pcDNA3-ApVGLUT; clone 9-2 pcDNA3). Lanes 1 and 2, Transcripts of ApVGLUT for clones $7-1$ and $9-2$ were not detected if reverse transcriptase was omitted from reaction mixture. Lane 3, PCR product was not detected in clone $9-2$ (vector alone). Lane 4, PCR product with specific primers was detected in clone 7-1. M, Marker lane. $\boldsymbol{B}$, Cellular localization of ApVGLUT protein stably expressed in COS7 cells. B1, Stable line COS7 cells transfected with vector $\mathrm{pcDNA3}$ alone. No staining was observed. $\mathbf{B 2}$, Stable line COS7 cells transfected with pcDNA3-ApVGLUT. Scale bar, $20 \mu \mathrm{m}$. C, Glutamate uptake by COS7 cells. The cell lines transfected with vector alone exhibited significantly less glutamate retention. Omitting ATP, which is required to maintain the proton gradient that enables uptake of glutamate into vesicles, also reduces glutamate retention. Inhibiting glutamate uptake via disruption of the proton gradient (40 $\mu \mathrm{m} \mathrm{FCCP}$ and $1 \mu \mathrm{m}$ bafilomycin) also reduces glutamate retention. Competitive inhibition of ApVGLUT with $5 \mu \mathrm{m}$ Evans blue or with $1 \mathrm{~mm}$ unlabeled glutamate (Glu) also reduced uptake of labeled glutamate. Competitive inhibition of ApVGLUT was not produced by $1 \mathrm{~mm}$ D-or L-aspartate (ASP). $t$ test: ${ }^{* *} p<0.01 ;{ }^{* * *} p<0.001$. Error bars indicate SEM.

showed that the ApVGLUT message was expressed in the cell bodies of neurons in buccal and cerebral ganglia (Fig. 5). Somata of identified glutamatergic neurons in the rostral buccal ganglion (i.e., the motor neuron B38 and a sensory neuron B21; Fig. 5, arrows) were labeled.

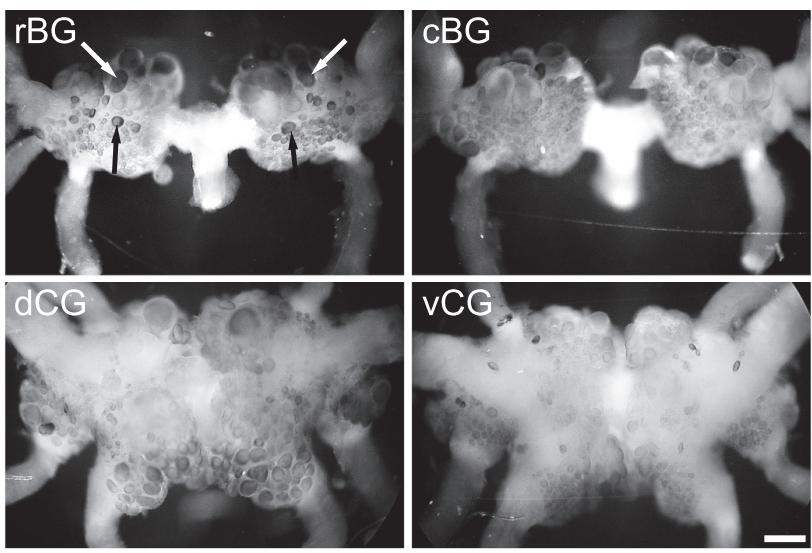

Figure 5. In situ hybridization of ApVGLUT in buccal and cerebral ganglia. Based on their location in the rostral buccal ganglion, putative B38 (white arrows) and B21 (black arrows) were indicated. $r B G$, rostral buccal ganglion; $\mathrm{CBG}$, caudal buccal ganglion; $\mathrm{dCG}$, dorsal cerebral ganglion; $V C G$, ventral cerebral ganglion. Scale bar, $200 \mu \mathrm{m}$.

In other experiments, we mapped the distribution of ApVGLUT in the buccal and cerebral ganglia using the two antibodies we had generated (Fig. 6). Immunostaining patterns with the two antibodies were similar. We also stained pleural-pedal ganglia and the abdominal ganglion. In general, ApVGLUT immunoreactivity is observed in all ganglia and is most intense in the neuropil. The staining pattern in the somata of the buccal and cerebral ganglia was similar to the staining pattern observed with ISH (Fig. 5) suggesting that our antibodies are specific. For example, the cell body of B38 was immunopositive. Previously, although the axons of $\mathrm{B} 38$ were stained with an antibody against glutamate, its cell body was not stained (Fox and Lloyd, 1999). Thus, our data obtained using RDA, ISH, and immunohistochemistry all complement previous work, reinforcing the idea that B38 is glutamatergic. Further, our antibodies against ApVGLUT offer a better way to identify novel glutamatergic neurons because cell bodies are labeled.

Using the same antibody (iCT), we performed Western blot (Fig. 7) with intact ganglia, and found that the buccal, cerebral, and pleural-pedal ganglia had various levels of ApVGLUT, while the abdominal ganglion had the least.

Because ApVGLUT was found through RDA with B64, we performed double-labeling experiments to determine whether B64 is ApVGLUT positive. We physiologically identified B64 and injected it with carboxyfluorescein, and then performed in situ hybridization and immunohistochemistry staining with two ApVGLUT antibodies. Indeed, B64 was double labeled, indicating that B64 contains ApVGLUT mRNA (Fig. 8A) and is ApVGLUT immunoreactive (Fig. $8 B, C$ ).

\section{Pharmacological profiles of B64 synaptic connections are} consistent with their glutamatergic nature

The data described above show that ApVGLUT derived through RDA performed on B38 and B64 is likely to be a vesicular glutamate transporter (i.e., it does indeed transport glutamate). ApVGLUT is present in the CNS, in the interneuron B64. This suggests that B64 is glutamatergic. To seek further evidence we performed pharmacological experiments, during which highdivalent saline was used to suppress polysynaptic influences.

B64 is a feeding central pattern-generating (CPG) interneuron (Hurwitz and Susswein, 1996; Jing et al., 2003; Wu et al., 2007) that is active during the retraction phase of feeding motor 


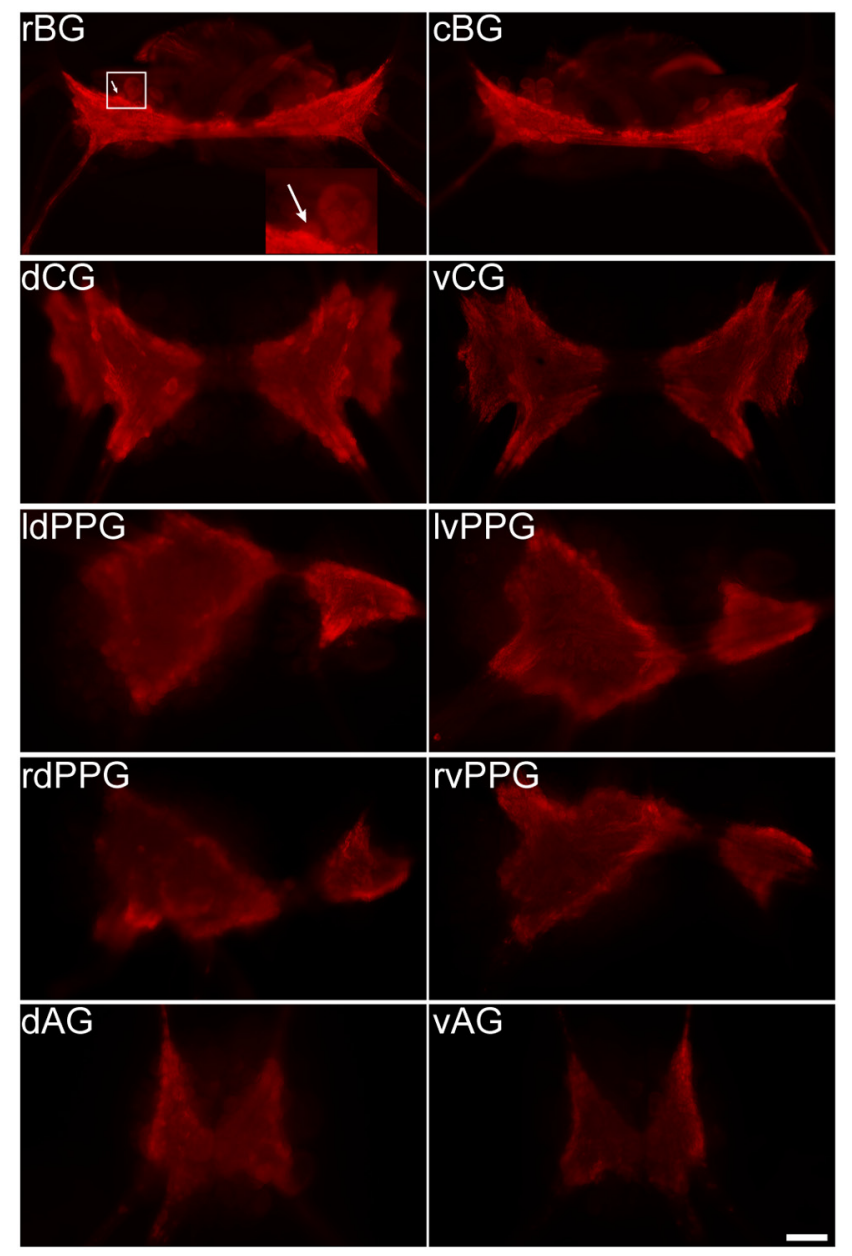

Figure 6. Immunocytochemistry of ApVGLUT in the Aplysia CNS. Immunostaining reveals that the majority of the ApVGLUT protein is located in theneuropil and intenseimmunostaining of the neuropil is observed in all ganglia. Based on its location in the rostral buccal ganglion, a putative B38 (arrow) wasidentified. The antibody against ApVGLUT was iCT.rBG, rostral buccal ganglion; $\mathrm{CBG}$, caudal buccal ganglion; $\mathrm{dCG}$, dorsal cerebral ganglion; $\mathrm{VCG}$, ventral cerebral ganglion; IdPPG, left dorsal pleural and pedal ganglia; IVPPG, left ventral pleural and pedal ganglia; rdPPG, right dorsal pleural and pedal ganglia; $r \mathrm{VPG}$, right ventral pleural and pedal ganglia; $\mathrm{dAG}$, dorsal abdominal ganglion; $\mathrm{vAG}$, ventral abdominal ganglion; Scale bar, $200 \mu \mathrm{m}$.

programs. It is important for the initiation of retraction, and plays a critical role in phase switching from protraction to retraction by making inhibitory connections to protraction neurons (e.g., B61/62), and excitatory connections to neurons active during retraction (e.g., B3). To determine whether exogenous glutamate mimics the effects of B64 activity, we applied puffs of glutamate to both B3 and B61/62. As expected, glutamate induced a depolarizing response in $\mathrm{B} 3$ and a hyperpolarizing response in B61/62 (Fig. 9A; $n=3$ ). In an attempt to occlude effects of transmitter released by B64, we perfused preparations with 1 and $10 \mathrm{~mm}$ glutamate. Glutamate at $10 \mathrm{~mm}$ occluded both EPSPs in B3 $\left(34.9 \%\right.$ of the control, $\left.F_{(3,6)}=8.53 ; p<0.05\right)$ and IPSPs in B61/62 (35.6\% of the control, $\left.F_{(3,6)}=12.54 ; p<0.01\right)$ elicited by B64 (Fig. 9C; $n=3$ ). Notably, although the unitary PSPs from B64 to its postsynaptic followers were generally too small to be discernible, we did observe that the monosynaptic IPSPs from B64 to B61/62 followed presynaptic spikes one for one (Fig. 9B). The data suggested that B64-elicited synaptic responses are at least partially fast PSPs.

EPSPs at glutamatergic synapses in mammals are sensitive to CNQX (Honoré et al., 1988; Davies and Collingridge, 1990). CNQX

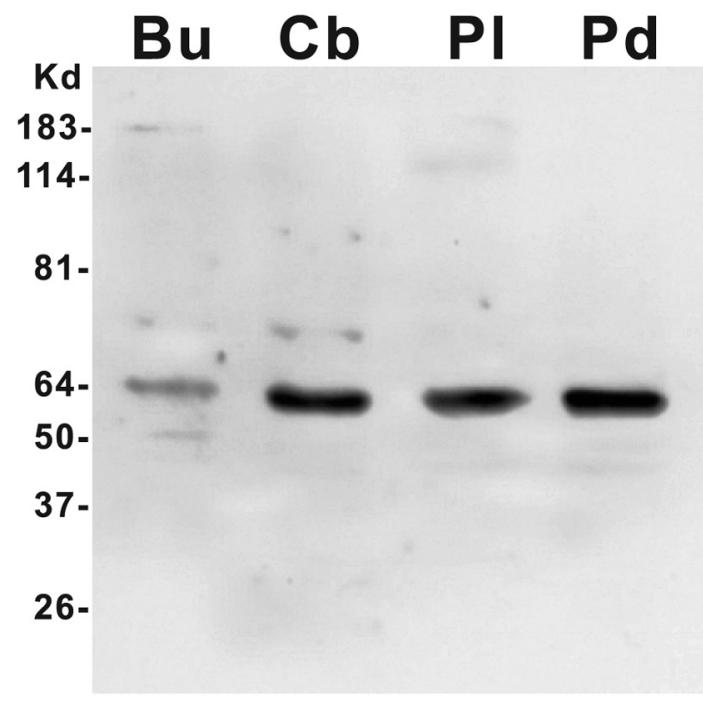

Figure 7. Western blot of ApVGLUT protein in the Aplysia CNS. Fractions prepared from ganglia (50 $\mu \mathrm{g} /$ lane) were solubilized, electrophoresed, and then subjected to Western blotting with an anti-ApVGLUT antibody (rat; 1:2000). The position of the marker (Kd) is shown. The antibody against ApVGLUT was iCT. Bu, buccal ganglion; Cb, cerebral ganglion; Pl, pleural ganglion; Pd, pedal ganglion; Ab, abdominal ganglion.
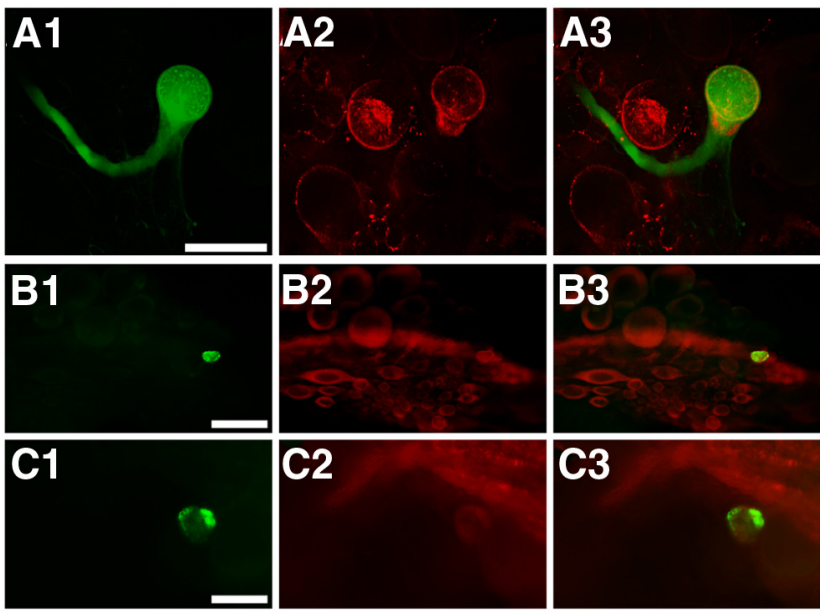

Figure 8. B64 is ApVGLUT positive. A1-C1, B64 injected with carboxyfluorescein. In situ hybridization ( $A 2$ ) and immunostaining ( $B 2$ and $(2)$. $A 3, B 3, C 3$, Merged images of the left and middle panels. $\boldsymbol{A}$, In situ hybridization (A2) shows that B64 (A3) expresses ApVGLUT mRNA. $\boldsymbol{B}, \boldsymbol{C}$, Immunostaining with two different antibodies to ApVGLUT, one to the $C$ terminus (iCT;B2) and one to the $N$ terminus (iNT; $C 2)$ of ApVGLUT, shows that B64 $(B 3, C 3)$ contains the ApVGLUT protein. Scale bars: $\boldsymbol{A}, 100 \mu \mathrm{m} ; \boldsymbol{B}$ (iCT), $200 \mu \mathrm{m}$; $\boldsymbol{C}$ (iNT), $100 \mu \mathrm{m}$.

is also an effective glutamatergic antagonist in Aplysia (Trudeau and Castellucci, 1993; Sasaki et al., 2007), Lymnaea (Brierley et al., 1997), and Tritonia (Megalou et al., 2009). We found that CNQX reduced B64-induced EPSPs in $\mathrm{B} 3$ to $35.5 \%$ of control values (Fig. $10 A ; F_{(2,4)}$ $=20.91 ; p<0.01 ; n=3)$. CNQX had no effect on B64-induced IPSPs in B61/62 $\left(F_{(2,4)}=3.61 ; p>0.05 ; n=3\right)$. Note that the incomplete occlusion and incomplete block by the relatively high concentration of the above pharmacological reagents were likely due to incomplete penetration of reagents to synaptic sites in the neuropil, which is deep in the ganglia.

Quisqualic acid (QA) activates a glutamate-mediated K-current in Aplysia (Katz and Levitan, 1993). IPSPs can result from the induction of $\mathrm{K}$-currents. We determined the reversal potential of B64-elicited IPSPs in contralateral B61/62 and found that it was 

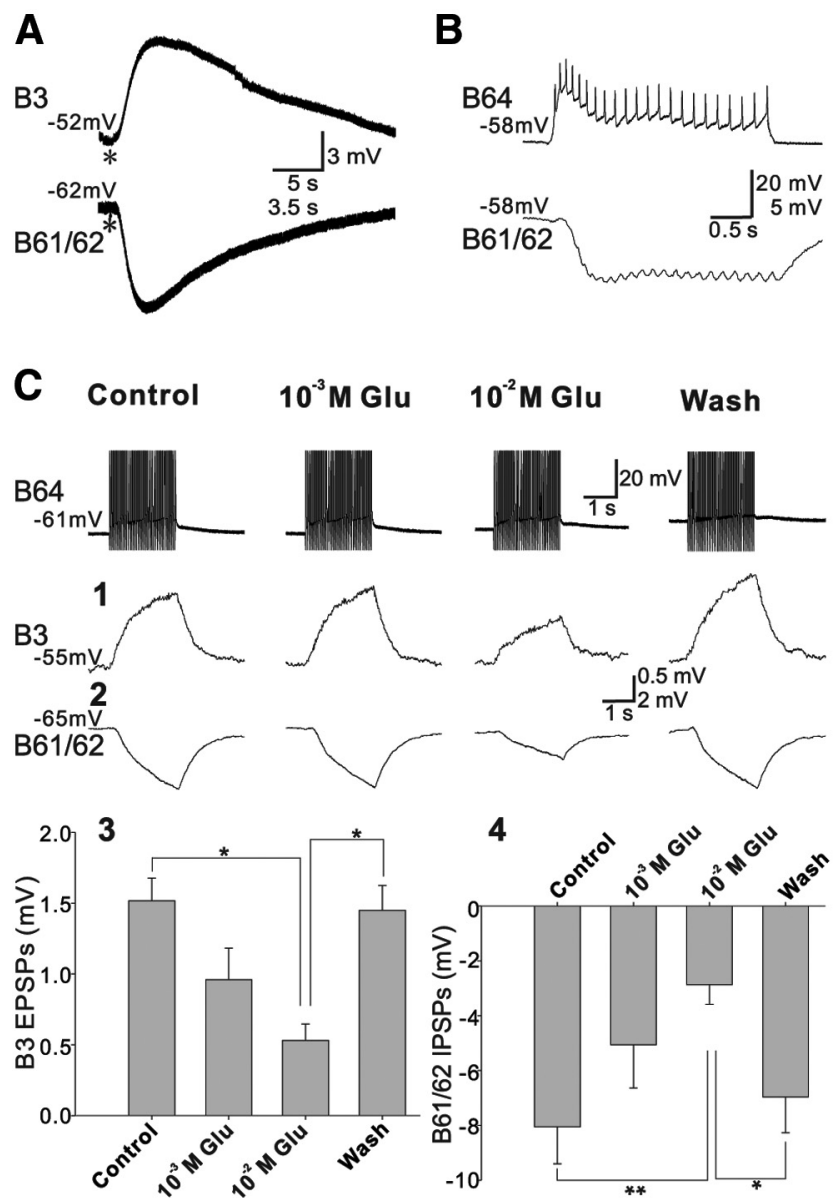

Figure 9. Glutamate effects on excitatory and inhibitory synapses of B64. A, Glutamate puff. Glutamate puffs (1 mM, asterisk) elicit depolarizing responses in $B 3$ and hyperpolarizing responses in B61/62. B, B64 elicits IPSPs in B61/62 that follow presynaptic spikes one for one. C, Desensitization experiments. EPSPs in B3 elicited by contralateral B64 are occluded by $10 \mathrm{~mm}$ glutamate ( $\mathbf{C}$, summary data in (3). In addition, IPSPs in B61/62 elicited by the contralateral B64 are also occluded by $10 \mathrm{~mm}$ glutamate ( $\boldsymbol{C}$, summary data in $\mathbf{C}$ ). B64 was stimulated at 20 $\mathrm{Hz}$ for $2 \mathrm{~s}$. Recordings were made in high-divalent saline to suppress polysynaptic effects, except $\boldsymbol{B}$, which was made in normal saline. Bonferroni post hoc tests: ${ }^{*} p<0.05 ;{ }^{* *} p<0.01$. Error bars indicate SEM. Numbers at the beginning of traces are membrane potentials (in millivolts).

$-92.75 \pm 1.79 \mathrm{mV}(n=4)$. We might have overestimated the reversal potential because the synaptic contact between B64 and B61/62 might be distant from the soma. Regardless, the reversal potential is closer to $\mathrm{K}$ equilibrium potential rather than to $\mathrm{Cl}$ equilibrium potential, because previous work (Brown et al., 1970) indicated that in Aplysia neurons the equilibrium potential of $\mathrm{K}$ is approximately $-80 \mathrm{mV}$, whereas that of $\mathrm{Cl}$ is approximately $-57 \mathrm{mV}$. This is consistent with the idea that $\mathrm{K}$-current mediates IPSPs in B61/62. We then sought to determine whether bath application of $10^{-5} \mathrm{M}$ QA could occlude B64-induced IPSPs in B61/62. Our data indicate that this was the case (Fig. $10 B ; F_{(2,6)}$ $=106.3 ; p<0.0001 ; n=4)$. Nonetheless, it has been previously shown that glutamatergic IPSPs in invertebrate CNS may be related to activation of chloride channels (Cleland, 1996), which can be blocked by picrotoxin. We therefore tested the effects of $10^{-4} \mathrm{M}$ picrotoxin on the IPSPs from B64 to B61/62 (data not shown) and found that it had no significant effect on the amplitude of the compound IPSPs (Control: $-3.64 \pm 0.65 \mathrm{mV}$; picrotoxin: $-3.38 \pm 0.64 \mathrm{mV}$; Wash: $-3.29 \pm 0.62 \mathrm{mV} ; F_{(2,6)}=2.92$; $p>0.05 ; n=4)$, thus further supporting the idea that the IPSPs from $\mathrm{B} 64$ to $\mathrm{B} 61 / 62$ are mediated by $\mathrm{K}$.
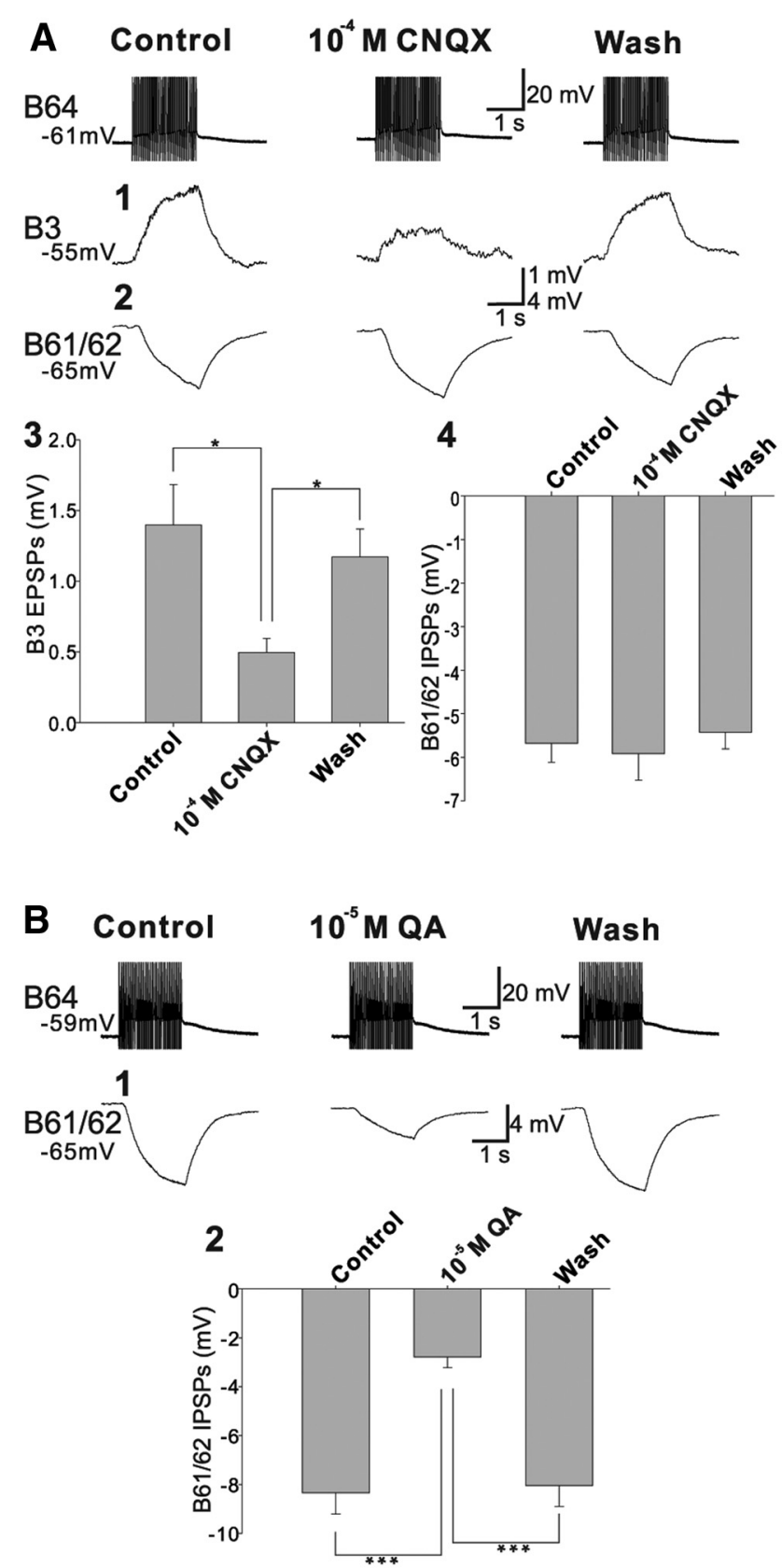

Figure 10. Pharmacological profiles of excitatory and inhibitory synapses of B64. A, The glutamate antagonist, $10^{-4} \mathrm{M} C \mathrm{CNQ}$, abolishes B64-elicited EPSPs in $\mathrm{B} 3(\boldsymbol{A} 1$, summary data in A3) but has no effect on B64-elicited IPSPs in B61/62 (A2, summary data in $A 4$ ). $B$, QA at $10^{-5}$ M occluded the IPSPs from B64 to B61/62 (B1, summary data in B2). B64 was stimulated at 20 $\mathrm{Hz}$ for $2 \mathrm{~s}$. All recordings were made in high-divalent saline. Bonferroni post hoc tests: ${ }^{*} p<$ $0.05 ;{ }^{* *} p<0.01 ;{ }^{* * *} p<0.001$. Error bars indicate SEM. Numbers at the beginning of traces are membrane potentials (in millivolts).

These data provide pharmacological evidence that supports the identification of B64 as a glutamatergic neuron that uses glutamate to exert both excitatory and inhibitory actions in the Aplysia feeding circuit.

\section{Discussion}

ApVGLUT and other vesicular glutamate transporters: evolutionary implications

One major goal of this study was to determine whether our RDA approach, initially used to identify abundantly expressed neuro- 
peptides, can also be used to identify larger proteins that may be expressed in limited amounts. We show that RDA can in fact be effective for this purpose. Importantly, we verified the expression and function of an Aplysia VGLUT using a variety of approaches, including in situ hybridization, immunocytochemistry, and cell biological and pharmacological techniques.

Taking advantage of the considerable sequence information available for VGLUTs, we used bioinformatics to determine how ApVGLUT relates to other proteins. Not surprisingly, ApVGLUT is most closely related to VGLUTs from three other molluscs, e.g., Lymnaea (Hatakeyama et al., 2010). Intriguingly, both our sequence comparison (Table 1) and phylogenetic analysis (Fig. 3) showed that outside of molluscs, ApVGLUT is more closely related to mammalian VGLUTs than to homologous proteins in two other invertebrates, C. elegans and Drosophila. A similar result has been obtained in other studies that have compared Aplysia proteins (Moroz et al., 2006) or miRNA (Rajasethupathy et al., 2009) to C. elegans and Drosophila molecules (see also Hatakeyama et al., 2010). Such findings provide additional impetus for continued studies of the Aplysia model system.

VGLUTs in mammals (and zebrafish) have been divided into three major types, i.e., VGLUT1, VGLUT2, and VGLUT3. Although the biochemical properties of the three mammalian isoforms are similar, they do differ in their distributions within the CNS (El Mestikawy et al., 2011; Omote and Moriyama, 2013). There is one major outstanding question: Do invertebrates (including Aplysia) have more than one type of VGLUT? Curiously, existing data in C. elegans (Lee et al., 1999; Chalasani et al., 2007; Serrano-Saiz et al., 2013) and Drosophila (Daniels et al., 2004) indicate that there is only one VGLUT. Intriguingly, lamprey, a primitive vertebrate, appears to have only one VGLUT as well (Villar-Cerviño et al., 2010). Thus, apparently, before zebrafish (Higashijima et al., 2004; Obholzer et al., 2008) there is only one confirmed VGLUT in each species. In contrast, it has been suggested that oysters (Crassostrea gigas) have three VGLUTs (Zhang et al., 2012); however, whether these proteins are actually expressed and function to transport glutamate has not been established. In Aplysia and Lymnaea, one VGLUT has been characterized, but genomic data in Aplysia suggest that there may be an additional VGLUT. Additionally, previous work in Aplysia (Dale and Kandel, 1993) indicates that sensory neurons in the pleural ganglion appear to be glutamatergic (but see Trudeau and Castellucci, 1993). Interestingly, we found that these neurons were not stained by our ApVGLUT antibody (Fig. 6). This raises the possibility that additional VGLUTs may exist in Aplysia. Thus, in future studies, it will be of interest to determine whether there is more than one type of VGLUT in invertebrates in general and in Aplysia in particular.

In previous studies conducted on Drosophila and C. elegans, expression of VGLUT genes has been manipulated to demonstrate that glutamatergic synaptic transmission is altered (Lee et al., 1999; Daniels et al., 2004, 2006). This suggests that invertebrate VGLUTs transport glutamate. To the best of our knowledge, however, the present study is the first to use cell biological techniques to directly demonstrate that this is the case. Specifically, we showed that ApVGLUT expressed in COS7 cells transports glutamate, but not aspartate. Moreover, the transport by ApVGLUT is similar to those by mammalian VGLUTs (Roseth et al., 1995; Bellocchio et al., 2000; Hayashi et al., 2001; Omote and Moriyama, 2013), because it is also dependent on ATP and a proton gradient and has a similar pharmacological profile.

\section{Glutamatergic actions in Aplysia feeding circuit}

In this study, we generated ApVGLUT antibodies, which present a novel reliable way to identify glutamatergic neurons in neural circuits of Aplysia. There is considerable interest in these neurons since glutamate is the primary excitatory neurotransmitter in the mammalian CNS (Jahr and Lester, 1992). In Aplysia, neurons are re-identifiable, which makes them particularly well suited for circuitry studies. Previous experiments have demonstrated that sensory neurons in the gill-withdrawal reflex circuit are glutamatergic (Dale and Kandel, 1993), and in the feeding circuit, some sensory neurons, like B21 (Klein et al., 2000), and motoneurons, like B38 (Fox and Lloyd, 1999), appear to be glutamatergic. Despite this progress, glutamatergic neurons have been difficult to identify in general because significant levels of glutamate may be present in neurons that do not release glutamate. Consequently, it had been hypothesized that glutamate might be the neurotransmitter for some feeding CPG neurons, e.g., B64, but this had not been directly confirmed.

The Aplysia feeding circuit generates a rhythmic pattern of repetitive protraction-retraction sequences (Cropper et al., 2004; Jing, 2009; Jing et al., 2009), with protraction initiated first followed by retraction. Previous work has shown that many critical neurons that play important roles in the generation of protraction are cholinergic. These neurons include commandlike neurons, cerebral-buccal interneuron-2 (CBI-2) and -11 (CBI-11), buccal interneurons B50, and CPG interneurons, B63 and B34 (Dembrow et al., 2003, 2004; Hurwitz et al., 2003; Wu et al., 2014). Our recent work suggests that CBI-10, another command-like neuron, is also cholinergic (S.-A. Chen, T.-T. Chen, K. Yu, D.-D. Liu, F.S. Vilim, E.C. Cropper, K.R. Weiss, J. Jing, unpublished observations). Because a feeding cycle is initiated when protraction begins, these data indicate that cholinergic actions are critical for the initiation of feeding behavior. Notably, consistent with a role in initiating activity, cholinergic transmission between these protraction neurons and follower cells is primarily excitatory.

In contrast, before the present study, it was unclear what transmitter plays a major role in the generation of retraction. Our present study indicates that B64, which is critical for the generation of retraction (Hurwitz and Susswein, 1996; Jing et al., 2003; Wu et al., 2007), is glutamatergic. This is supported by a number of findings. Namely, we characterized ApVGLUT using RDA with B64. B64 is ApVGLUT immunoreactive, and pharmacological agents that impact glutamatergic transmission at other synapses affect synaptic transmission between B64 and follower neurons. Importantly, B64 serves a dual role in retraction as it suppresses the activity of protraction neurons (e.g., B61/62) to help terminate protraction and excites retraction neurons (e.g., B3) to sustain retraction. Thus, B64 elicits both excitatory and inhibitory PSPs on target neurons, i.e., EPSPs in B3 and IPSPs in B61/62 (Hurwitz and Susswein, 1996). Our pharmacological evidence indicates that both the excitatory and inhibitory contacts made by B64 are glutamatergic. Notably, although previous work indicated that glutamatergic IPSPs in invertebrate CNS (Cleland, 1996) may be related to activation of a $\mathrm{Cl}$ ion channel, our data suggest that B64 to B61/62 IPSPs are likely mediated by $\mathrm{K}$ rather than $\mathrm{Cl}$. This is suggested by their reversal potential, their sensitivity to QA, and their insensitivity to picrotoxin. Regardless, the present findings have two major implications. First, our study supports the idea that glutamate may be an important transmitter in the generation of retraction (Sasaki et al., 2007) by implementing the dual role of B64 in the feeding circuit. Second, and more generally, these data suggest that the Aplysia feeding circuit may 
be different from neural circuits in the mammalian CNS, in that in mammalian circuits glutamate may be the primary excitatory transmitter, whereas in Aplysia, glutamate may play a secondary role as it acts both as an excitatory and inhibitory transmitter. This may also be true in other molluscs, e.g., Lymnaea (Benjamin, 2012). As more neural circuits in molluscs are elucidated, it would be of interest to determine what kinds of roles ACh and glutamate may play in neural circuits other than the feeding circuit.

In summary, we used a multidisciplinary approach to identify and characterize the vesicular glutamate transporter in Aplysia. We have successfully shown that B64, a critical interneuron in the Aplysia feeding circuit, is ApVGLUT positive and uses glutamate to mediate both excitatory and inhibitory synaptic transmission. Thus, our studies might be expected to facilitate the study of glutamatergic neurons in neural circuits of Aplysia. More generally, our RDA-based approach should also be readily adaptable to other model systems with identifiable neurons.

\section{References}

Bai L, Livnat I, Romanova EV, Alexeeva V, Yau PM, Vilim FS, Weiss KR, Jing J, Sweedler JV (2013) Characterization of GdFFD, a D-amino acidcontaining neuropeptide that functions as an extrinsic modulator of the Aplysia feeding circuit. J Biol Chem 288:32837-32851. CrossRef Medline

Bellocchio EE, Reimer RJ, Fremeau RT Jr, Edwards RH (2000) Uptake of glutamate into synaptic vesicles by an inorganic phosphate transporter. Science 289:957-960. CrossRef Medline

Benjamin PR (2012) Distributed network organization underlying feeding behavior in the mollusk Lymnaea. Neural Syst Circuits 2:4. CrossRef Medline

Brierley MJ, Yeoman MS, Benjamin PR (1997) Glutamate is the transmitter for $\mathrm{N} 2 \mathrm{v}$ retraction phase interneurons of the Lymnaea feeding system. J Neurophysiol 78:3408-3414. Medline

Brown AM, Sutton RB, Walker JL Jr (1970) Increased chloride conductance as the proximate cause of hydrogen ion concentration effects in Aplysia neurons. J Gen Physiol 56:559-582. CrossRef Medline

Byrne JH, Castellucci VF, Kandel ER (1978) Contribution of individual mechanoreceptor sensory neurons to defensive gill-withdrawal reflex in Aplysia. J Neurophysiol 41:418-431. Medline

Chalasani SH, Chronis N, Tsunozaki M, Gray JM, Ramot D, Goodman MB, Bargmann CI (2007) Dissecting a circuit for olfactory behaviour in Caenorhabditis elegans. Nature 450:63-70. CrossRef Medline

Cleland TA (1996) Inhibitory glutamate receptor channels. Mol Neurobiol 13:97-136. CrossRef Medline

Collado MS, Lyons LC, Levenson JM, Khabour O, Pita-Almenar JD, Schrader L, Eskin A (2007) In vivo regulation of an Aplysia glutamate transporter, ApGT1, during long-term memory formation. J Neurochem 100:13151328. CrossRef Medline

Cropper EC, Evans CG, Hurwitz I, Jing J, Proekt A, Romero A, Rosen SC (2004) Feeding neural networks in the mollusc Aplysia. Neurosignals 13:70-86. CrossRef Medline

Dale N, Kandel ER (1993) L-glutamate may be the fast excitatory transmitter of Aplysia sensory neurons. Proc Natl Acad Sci U S A 90:7163-7167. CrossRef Medline

Daniels RW, Collins CA, Gelfand MV, Dant J, Brooks ES, Krantz DE, DiAntonio A (2004) Increased expression of the Drosophila vesicular glutamate transporter leads to excess glutamate release and a compensatory decrease in quantal content. J Neurosci 24:10466-10474. CrossRef Medline

Daniels RW, Collins CA, Chen K, Gelfand MV, Featherstone DE, DiAntonio A (2006) A single vesicular glutamate transporter is sufficient to fill a synaptic vesicle. Neuron 49:11-16. CrossRef Medline

Davies SN, Collingridge GL (1990) Quinoxalinediones as excitatory amino acid antagonists in the vertebrate central nervous system. Int Rev Neurobiol 32:281-303. CrossRef Medline

Dembrow NC, Jing J, Proekt A, Romero A, Vilim FS, Cropper EC, Weiss KR (2003) A newly identified buccal interneuron initiates and modulates feeding motor programs in Aplysia. J Neurophysiol 90:2190-2204. CrossRef Medline

Dembrow NC, Jing J, Brezina V, Weiss KR (2004) A specific synaptic path- way activates a conditional plateau potential underlying protraction phase in the Aplysia feeding central pattern generator. J Neurosci 24: 5230-5238. CrossRef Medline

El Mestikawy S, Wallén-Mackenzie A, Fortin GM, Descarries L, Trudeau LE (2011) From glutamate co-release to vesicular synergy: vesicular glutamate transporters. Nat Rev Neurosci 12:204-216. CrossRef Medline

Fox LE, Lloyd PE (1999) Glutamate is a fast excitatory transmitter at some buccal neuromuscular synapses in Aplysia. J Neurophysiol 82:1477-1488. Medline

Fujisawa Y, Furukawa Y, Ohta S, Ellis TA, Dembrow NC, Li L, Floyd PD, Sweedler JV, Minakata H, Nakamaru K, Morishita F, Matsushima O, Weiss KR, Vilim FS (1999) The Aplysia mytilus inhibitory peptiderelated peptides: identification, cloning, processing, distribution, and action. J Neurosci 19:9618-9634. Medline

Furukawa Y, Nakamaru K, Wakayama H, Fujisawa Y, Minakata H, Ohta S, Morishita F, Matsushima O, Li L, Romanova E, Sweedler JV, Park JH, Romero A, Cropper EC, Dembrow NC, Jing J, Weiss KR, Vilim FS (2001) The enterins: a novel family of neuropeptides isolated from the enteric nervous system and CNS of Aplysia. J Neurosci 21:8247-8261. Medline

Hatakeyama D, Mita K, Kobayashi S, Sadamoto H, Fujito Y, Hiripi L, Elekes $\mathrm{K}$, Ito E (2010) Glutamate transporters in the central nervous system of a pond snail. J Neurosci Res 88:1374-1386. CrossRef Medline

Hayashi M, Otsuka M, Morimoto R, Hirota S, Yatsushiro S, Takeda J, Yamamoto A, Moriyama Y (2001) Differentiation-associated Na+dependent inorganic phosphate cotransporter (DNPI) is a vesicular glutamate transporter in endocrine glutamatergic systems. J Biol Chem 276: 43400-43406. CrossRef Medline

Higashijima S, Mandel G, Fetcho JR (2004) Distribution of prospective glutamatergic, glycinergic, and GABAergic neurons in embryonic and larval zebrafish. J Comp Neurol 480:1-18. CrossRef Medline

Honoré T, Davies SN, Drejer J, Fletcher EJ, Jacobsen P, Lodge D, Nielsen FE (1988) Quinoxalinediones: potent competitive non-NMDA glutamate receptor antagonists. Science 241:701-703. CrossRef Medline

Hubank M, Schatz DG (1994) Identifying differences in mRNA expression by representational difference analysis of cDNA. Nucleic Acids Res 22: 5640-5648. CrossRef Medline

Hurwitz I, Susswein AJ (1996) B64, a newly identified central pattern generator element producing a phase switch from protraction to retraction in buccal motor programs of Aplysia californica. J Neurophysiol 75:13271344. Medline

Hurwitz I, Kupfermann I, Weiss KR (2003) Fast synaptic connections from CBIs to pattern-generating neurons in Aplysia: initiation and modification of motor programs. J Neurophysiol 89:2120-2136. CrossRef Medline

Jahr CE, Lester RA (1992) Synaptic excitation mediated by glutamate-gated ion channels. Curr Opin Neurobiol 2:270-274. CrossRef Medline

Jing J (2009) Command systems. In: Encyclopedia of neuroscience, Vol 2 (Squire LR, ed), pp 1149-1158. Oxford, UK: Academic.

Jing J, Weiss KR (2005) Generation of variants of a motor act in a modular and hierarchical motor network. Curr Biol 15:1712-1721. CrossRef Medline

Jing J, Vilim FS, Wu JS, Park JH, Weiss KR (2003) Concerted GABAergic actions of Aplysia feeding interneurons in motor program specification. J Neurosci 23:5283-5294. Medline

Jing J, Vilim FS, Horn CC, Alexeeva V, Hatcher NG, Sasaki K, Yashina I, Zhurov Y, Kupfermann I, Sweedler JV, Weiss KR (2007) From hunger to satiety: reconfiguration of a feeding network by Aplysia neuropeptide Y. J Neurosci 27:3490-3502. CrossRef Medline

Jing J, Gillette R, Weiss KR (2009) Evolving concepts of arousal: insights from simple model systems. Rev Neurosci 20:405-427. Medline

Jing J, Sweedler JV, Cropper EC, Alexeeva V, Park JH, Romanova EV, Xie F, Dembrow NC, Ludwar BC, Weiss KR, Vilim FS (2010) Feedforward compensation mediated by the central and peripheral actions of a single neuropeptide discovered using representational difference analysis. J Neurosci 30:16545-16558. CrossRef Medline

Katz PS, Levitan IB (1993) Quisqualate and ACPD are agonists for a glutamate-activated current in identified Aplysia neurons. J Neurophysiol 69:143-150. Medline

Klein AN, Weiss KR, Cropper EC (2000) Glutamate is the fast excitatory neurotransmitter of small cardioactive peptide-containing Aplysia radula mechanoafferent neuron B21. Neurosci Lett 289:37-40. CrossRef Medline 
Lee RY, Sawin ER, Chalfie M, Horvitz HR, Avery L (1999) EAT-4, a homolog of a mammalian sodium-dependent inorganic phosphate cotransporter, is necessary for glutamatergic neurotransmission in Caenorhabditis elegans. J Neurosci 19:159-167. Medline

Levenson J, Sherry DM, Dryer L, Chin J, Byrne JH, Eskin A (2000) Localization of glutamate and glutamate transporters in the sensory neurons of Aplysia. J Comp Neurol 423:121-131. CrossRef Medline

Li L, Floyd PD, Rubakhin SS, Romanova EV, Jing J, Alexeeva VY, Dembrow NC, Weiss KR, Vilim FS, Sweedler JV (2001) Cerebrin prohormone processing, distribution and action in Aplysia californica. J Neurochem 77:1569-1580. CrossRef Medline

Lin AH, Cohen JE, Wan Q, Niu K, Shrestha P, Bernstein SL, Abrams TW (2010) Serotonin stimulation of cAMP-dependent plasticity in Aplysia sensory neurons is mediated by calmodulin-sensitive adenylyl cyclase. Proc Natl Acad Sci U S A 107:15607-15612. CrossRef Medline

Lisitsyn N, Lisitsyn N, Wigler M (1993) Cloning the differences between two complex genomes. Science 259:946-951. CrossRef Medline

Lloyd PE, Mahon AC, Kupfermann I, Cohen JL, Scheller RH, Weiss KR (1985) Biochemical and immunocytological localization of molluscan small cardioactive peptides in the nervous system of Aplysia californica. J Neurosci 5:1851-1861. Medline

Megalou EV, Brandon CJ, Frost WN (2009) Evidence that the swim afferent neurons of Tritonia diomedea are glutamatergic. Biol Bull 216:103-112. Medline

Moroz LL, Edwards JR, Puthanveettil SV, Kohn AB, Ha T, Heyland A, Knudsen B, Sahni A, Yu F, Liu L, Jezzini S, Lovell P, Iannucculli W, Chen M, Nguyen T, Sheng H, Shaw R, Kalachikov S, Panchin YV, Farmerie W, et al. (2006) Neuronal transcriptome of Aplysia: neuronal compartments and circuitry. Cell 127:1453-1467. CrossRef Medline

Obholzer N, Wolfson S, Trapani JG, Mo W, Nechiporuk A, Busch-Nentwich E, Seiler C, Sidi S, Söllner C, Duncan RN, Boehland A, Nicolson T (2008) Vesicular glutamate transporter 3 is required for synaptic transmission in zebrafish hair cells. J Neurosci 28:2110-2118. CrossRef Medline

Omote H, Moriyama Y (2013) Vesicular neurotransmitter transporters: an approach for studying transporters with purified proteins. Physiology 28:39-50. CrossRef Medline

Rajasethupathy P, Fiumara F, Sheridan R, Betel D, Puthanveettil SV, Russo JJ, Sander C, Tuschl T, Kandel E (2009) Characterization of small RNAs in Aplysia reveals a role for miR-124 in constraining synaptic plasticity through CREB. Neuron 63:803-817. CrossRef Medline

Romanova EV, Sasaki K, Alexeeva V, Vilim FS, Jing J, Richmond TA, Weiss KR, Sweedler JV (2012) Urotensin II in invertebrates: from structure to function in Aplysia californica. PLoS One 7:e48764. CrossRef Medline

Roseth S, Fykse EM, Fonnum F (1995) Uptake of L-glutamate into rat-brain synaptic vesicles: effect of inhibitors that bind specifically to the glutamate transporter. J Neurochem 65:96-103. CrossRef Medline

Sasaki K, Due MR, Jing J, Weiss KR (2007) Feeding CPG in Aplysia directly controls two distinct outputs of a compartmentalized interneuron that functions as a CPG element. J Neurophysiol 98:3796-3801. CrossRef Medline

Serrano-Saiz E, Poole RJ, Felton T, Zhang F, De La Cruz ED, Hobert O (2013) Modular control of glutamatergic neuronal identity in C. elegans by distinct homeodomain proteins. Cell 155:659-673. CrossRef Medline

Sive HL, St John T (1988) A simple subtractive hybridization technique employing photoactivatable biotin and phenol extraction. Nucleic Acids Res 16:10937. CrossRef Medline

Sossin WS, Abrams TW (2009) Evolutionary conservation of the signaling proteins upstream of cyclic AMP-dependent kinase and protein kinase $\mathrm{C}$ in gastropod mollusks. Brain Behav Evol 74:191-205. CrossRef Medline

Sweedler JV, Li L, Rubakhin SS, Alexeeva V, Dembrow NC, Dowling O, Jing J, Weiss KR, Vilim FS (2002) Identification and characterization of the feeding circuit-activating peptides, a novel neuropeptide family of Aplysia. J Neurosci 22:7797-7808. Medline

Trudeau LE, Castellucci VF (1992) Contribution of polysynaptic pathways in the mediation and plasticity of Aplysia gill and siphon withdrawal reflex-evidence for differential modulation. J Neurosci 12:3838-3848. Medline

Trudeau LE, Castellucci VF (1993) Excitatory amino acid neurotransmission at sensory-motor and interneuronal synapses of Aplysia californica. J Neurophysiol 70:1221-1230. Medline

Vilim FS, Alexeeva V, Moroz LL, Li L, Moroz TP, Sweedler JV, Weiss KR (2001) Cloning, expression and processing of the CP2 neuropeptide precursor of Aplysia. Peptides 22:2027-2038. CrossRef Medline

Villar-Cerviño V, Rocancourt C, Menuet A, Da Silva C, Wincker P, Anadón R, Mazan S, Rodicio MC (2010) A vesicular glutamate transporter in lampreys: cDNA cloning and early expression in the nervous system. J Chem Neuroanat 40:71-81. CrossRef Medline

Wu JS, Due MR, Sasaki K, Proekt A, Jing J, Weiss KR (2007) State dependence of spike timing and neuronal function in a motor pattern generating network. J Neurosci 27:10818-10831. CrossRef Medline

Wu JS, Wang N, Siniscalchi MJ, Perkins MH, Zheng YT, Yu W, Chen SA, Jia RN, Gu JW, Qian YQ, Ye Y, Vilim FS, Cropper EC, Weiss KR, Jing J (2014) Complementary interactions between command-like interneurons that function to activate and specify motor programs. J Neurosci 34:6510-6521. CrossRef Medline

Zhang G, Fang X, Guo X, Li L, Luo R, Xu F, Yang P, Zhang L, Wang X, Qi H, Xiong Z, Que H, Xie Y, Holland PW, Paps J, Zhu Y, Wu F, Chen Y, Wang J, Peng C, et al. (2012) The oyster genome reveals stress adaptation and complexity of shell formation. Nature 490:49-54. CrossRef Medline 